\title{
A Roadmap for the Development of Health Information Technology in Chile
}

Erin Audrey Taylor, Shira H. Fischer, Tadeja Gracner, Ivo Tejeda, Alice Kim, Emilio R. Chavez-Herrerias, Fernando Hoces de la Guardia 
For more information on this publication, visit www.rand.org/t/RR1358z2

Published by the RAND Corporation, Santa Monica, Calif.

(C) Copyright 2016 RAND Corporation

RAND $^{\circledR}$ is a registered trademark.

Cover: caption/source information.

\section{Limited Print and Electronic Distribution Rights}

This document and trademark(s) contained herein are protected by law. This representation of RAND intellectual property is provided for noncommercial use only. Unauthorized posting of this publication online is prohibited. Permission is given to duplicate this document for personal use only, as long as it is unaltered and complete. Permission is required from RAND to reproduce, or reuse in another form, any of its research documents for commercial use. For information on reprint and linking permissions, please visit www.rand.org/pubs/permissions.

The RAND Corporation is a research organization that develops solutions to public policy challenges to help make communities throughout the world safer and more secure, healthier and more prosperous. RAND is nonprofit, nonpartisan, and committed to the public interest.

RAND's publications do not necessarily reflect the opinions of its research clients and sponsors.

Support RAND

Make a tax-deductible charitable contribution at www.rand.org/giving/contribute

www.rand.org 


\section{Preface}

The government in Chile has established 11 Strategic Programs, which are designed to foster the development of a given economic sector over the next ten years. As part of the health and development Strategic Program, the Ministry of Economy, Development and Tourism asked the RAND Corporation to create a roadmap to guide the development of health information technology (IT) in the public health system in Chile. This project had two phases. For the first phase of this project, we described the current health IT environment in Chile and identified the key opportunities and challenges associated with the growth of the sector. For the second phase, we designed a roadmap that focuses on key objectives and activities designed to encourage growth in adoption and successful implementation of health IT in the public sector in Chile. This report presents the results from the second phase. 



\section{Contents}

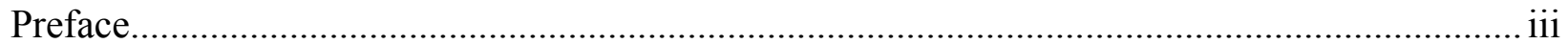

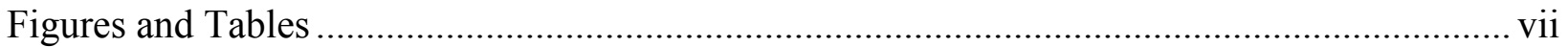

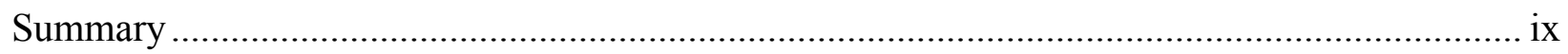

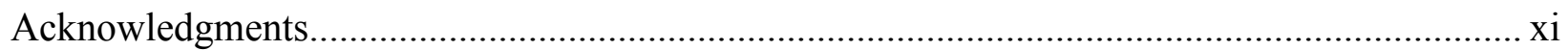

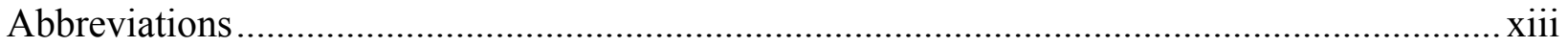

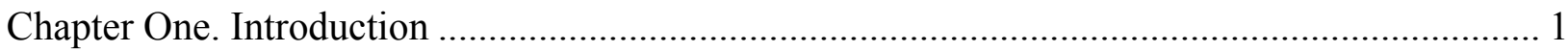

Key Challenges to Health Information Technology Development ..................................................... 1

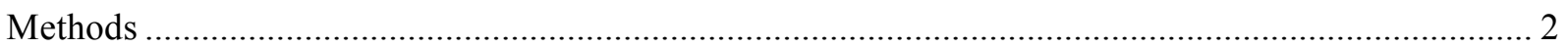

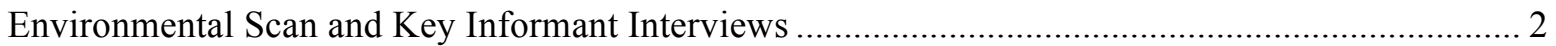

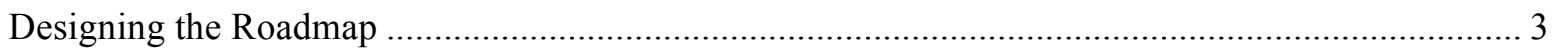

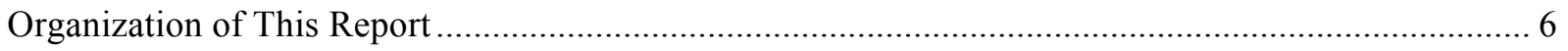

Chapter Two. A Roadmap to Foster the Development of Health Information Technology.......... 7

Objective 1: Develop Institutional Capacity to Facilitate and Monitor the Implementation of the

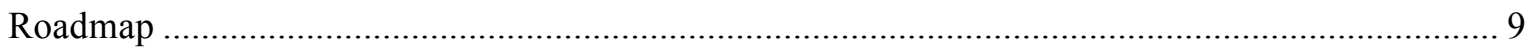

Create an Institution to Facilitate and Monitor Implementation ................................................... 10

Identify and Allocate the Resources Necessary to Accomplish Roadmap Activities ...................... 11

Create a Task Force to Determine Key Changes Necessary to Foster Health Information

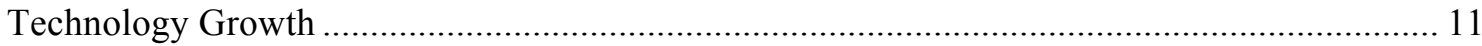

Provide Support to the Standard and Certification Organization ................................................ 13

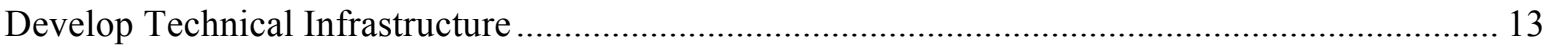

Objective 2: Successfully Implement and Broaden the Use of an Interoperable Online

Appointment, Referral, Medical Leave, and Integrated Payment System by 2021 ....................... 13

Evaluate Current National Health Fund Projects ........................................................................... 14

Determine the Evaluation Design and Measures of Success...................................................... 15

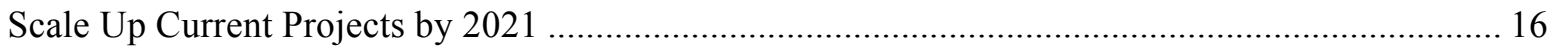

Collect Data to Evaluate the Success of Implementation Efforts..................................................... 16

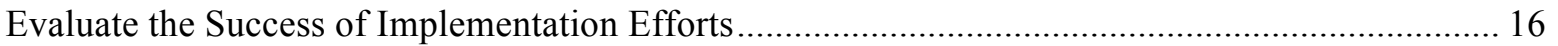

Objective 3: Scale Up Promising Telemedicine Projects That Target Prevention and Treatment of

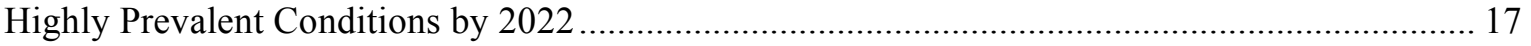

Establish Priorities for Identifying the Highest-Impact Telemedicine Projects ............................... 18

Identify the Most-Successful Existing Telemedicine Projects Through Rigorous Evaluation .......... 18

Establish Legal Regulations for Distance Care for Patients and Clinicians.................................... 19

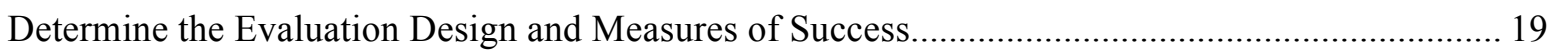

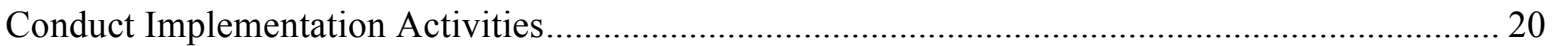

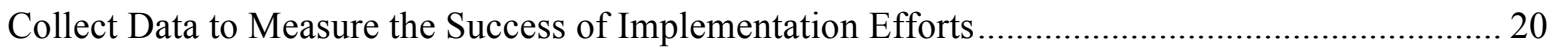

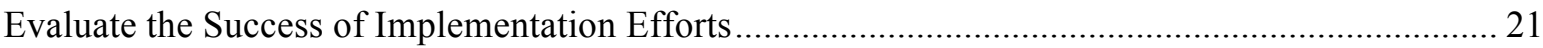


Objective 4: Successfully Implement an Interoperable Electronic Health Record in the Public

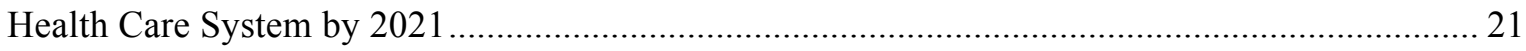

Establish Criteria for System Standards and Interoperability ...................................................... 22

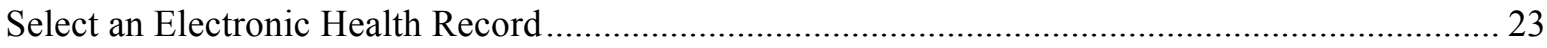

Determine the Evaluation Design and Measures of Success...................................................... 24

Establish an Incentive System to Encourage Adoption and Successful Implementation .................. 24

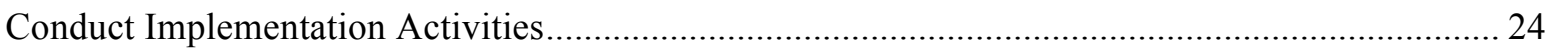

Collect Data to Evaluate the Success of the Implementation Efforts............................................ 25

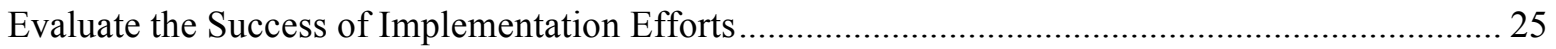

Objective 5: Implement a Trackable Computerized Pharmaceutical and Device Ordering System

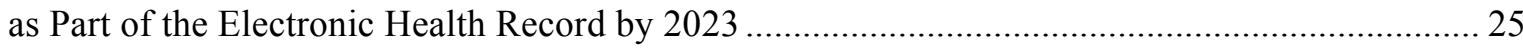

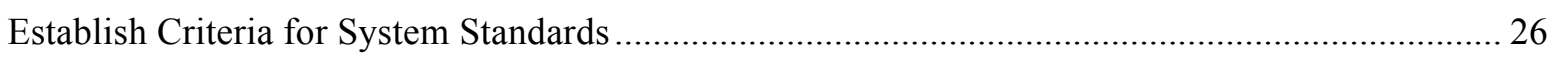

Select a System That Is Compatible with the National Electronic Health Record .......................... 26

Determine the Evaluation Design and Measures of Success...................................................... 27

Collect Data to Evaluate the Success of the Implementation Efforts............................................... 27

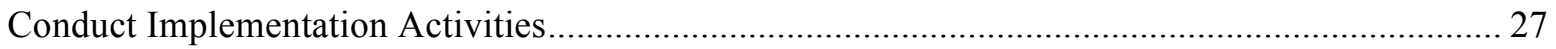

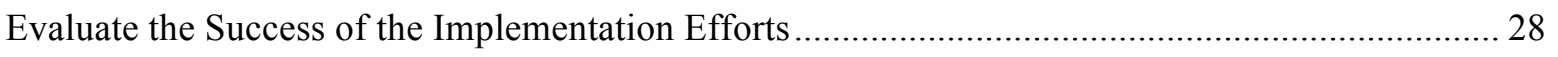

Chapter Three. Establishing Incentives to Encourage Health Information Technology

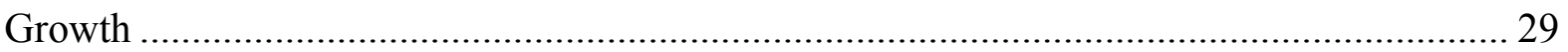

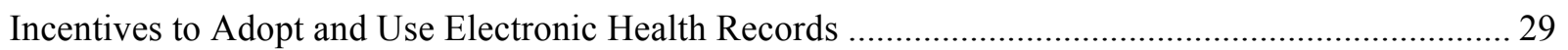

Incentives to Encourage Further Development and Use of Telemedicine ........................................ 31

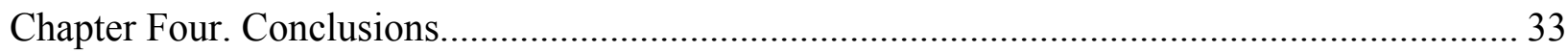

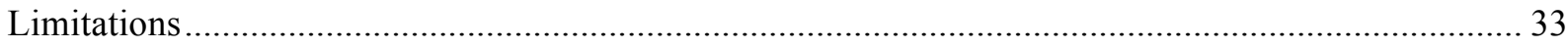

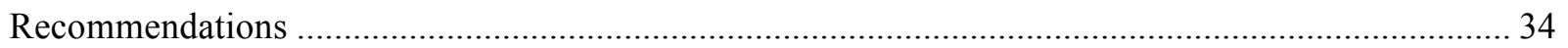

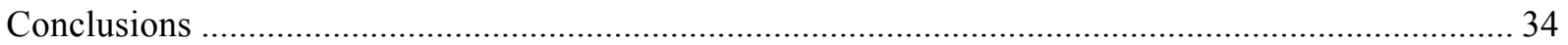

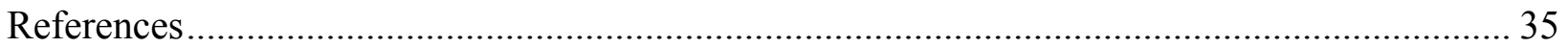


Figure 1.1. Conceptual Model for Designing the Roadmap .................................................. 4

Figure 2.1. Key Objectives of the Health Information Technology Roadmap........................... 7

Figure 2.2. Timeline for Achieving Roadmap Objectives ................................................. 8

Figure 2.3. Timeline for Key Activities to Achieve Objective 1 ........................................... 10

Figure 2.4. Timeline for Key Activities to Achieve Objective 2 ........................................... 14

Figure 2.5. Timeline for Key Activities to Achieve Objective 3 .......................................... 17

Figure 2.6. Timeline for Key Activities to Achieve Objective 4 .......................................... 22

Figure 2.7. Timeline for Key Activities to Achieve Objective 5 .......................................... 26

Table 2.1. Current Online Appointment, Referral, Medical Leave, and Payment Systems ........ 15

Table 2.2. Current Telemedicine Projects............................................................................... 18 



\section{Summary}

The Chilean government has established 11 Strategic Programs designed to foster the development of different economic sectors over the next ten years. As part of the health and development Strategic Program, the Ministry of Economy, Development and Tourism asked the RAND Corporation to create a roadmap to foster the development of health information technology (IT) in the public health system in Chile. For the first phase of this project, we conducted an environmental scan and key informant interviews designed to understand the current state of health IT in Chile, as well as to identify opportunities and challenges associated with the growth of health IT over the next ten years. The detailed methods and findings from the first phase are described in the first report for this project (Taylor, Fischer, Gracner, Tejeda, Kim, Chavez-Herrerias, et al., 2016).

Informed by the findings from the first phase of the project, as well as feedback from a briefing conducted with key stakeholders in Chile, we developed five objectives for the roadmap in consultation with the Ministry of Economy, Development and Tourism:

1. Develop institutional capacity to implement health IT projects.

2. Broaden use of interoperable online appointment and payment systems by 2021 .

3. Scale up existing telemedicine projects by 2022 .

4. Implement an interoperable electronic health record by 2021.

5. Implement a pharmaceutical and medical device tracking system by 2023 .

For each objective, we identified a series of activities that could be undertaken to achieve the objective, as well as a recommended timeline for starting and completing each activity. It is important to note that the activities and the timeline are guidelines. Key stakeholders should make the final selection of activities, determine the details related to those activities, and establish the specific timelines for the activities.

We also present the results of some additional research regarding the potential incentive programs Chile could implement to encourage the increased use of health IT. We generally found that other countries have implemented programs that tie provider payments to specific activities related to use of health IT. The programs in use in other countries have resulted in varying levels of successful implementation and use of health IT, which suggests that Chile should carefully weigh the pros and cons of each option before determining which program to adopt.

This study has some limitations. First, we could not estimate the inputs and resources necessary to achieve the roadmap objectives given the scope and timeline of this project, and we lacked available information regarding current projects in Chile and their associated resources and costs. A second limitation is that we conducted our key informant interviews with ten respondents. However, to try to incorporate as much information as possible, we also conducted 
a briefing for the board of governors and other interested stakeholders to obtain feedback on the proposed roadmap design. We have incorporated this feedback into the roadmap. A third limitation is the lack of publicly available information describing interactions and incentives within the Chilean health care system (e.g., how the public health insurer, the National Health Fund, or Fondo Nacional de Salud, reimburses public hospitals for services; the extent to which physicians work in the public versus private sector). This lack of information made it difficult to recommend specific incentive programs that might produce the desired level of uptake of a given health IT project within the Chilean system context.

Given our findings, we have three recommendations for the Ministry of Economy, Development and Tourism to consider when implementing the roadmap:

1. Develop the health IT workforce and other resources needed to successfully implement health IT projects.

2. Use incentive programs to encourage successful implementation of health IT projects.

3. Clearly define measures of success, and consistently collect baseline and follow-up data to assess success.

This roadmap is intended to serve as a guide for the Ministry of Economy, Development and Tourism and other key health IT stakeholders to foster the development of health IT in Chile over the next ten years. As noted above, the key stakeholders identified during the first phase of the project must determine the specific details for each activity included in the roadmap. We intend this roadmap to provide guidance regarding how key stakeholders might approach solving the challenges we addressed as part of the first phase of this project and to make recommendations related to how to approach a given implementation activity. 


\section{Acknowledgments}

We would like to thank some people who made important contributions to this report. These include Fabian Duarte, Robert S. Rudin, Paul Koegel, and Peter S. Hussey for their reviews and helpful comments on the report. We also thank the key informants who participated in the interviews, as well as those who attended the briefing, for their insightful comments and suggestions. Finally, we are grateful to Aisen Etcheverry, Paola Cañon Guidetti, and Cheryl L. Damberg for their feedback and guidance during both project phases. 



\section{Abbreviations}

\begin{tabular}{ll}
\hline EHR & electronic health record \\
\hline EU & European Union \\
FONASA & Fondo Nacional de Salud, or National Health Fund \\
ICD & International Classification of Diseases \\
IT & information technology \\
MINSAL & Ministerio de Salud, or Ministry of Health \\
ONC & Office of the National Coordinator for Health Information Technology \\
TTECG & transtelephonic electrocardiography
\end{tabular}





\section{Chapter One. Introduction}

The Chilean government has undertaken an effort called Strategic Programs for Smart Specialization (to which we refer in this report as Strategic Programs) to foster development in a variety of economic sectors. One of these programs is in the area of health and development, which includes a focus on the development of the health information technology (IT) sector within the public health care system in Chile. An early phase of the Strategic Programs involves the development of a roadmap to identify the key objectives and activities needed to meet the overall objective of health IT sector growth in Chile. We intend this roadmap to guide the Chilean government and other key stakeholders in planning and timing activities necessary to accomplish the key objectives and in establishing and measuring whether and to what extent objectives have been met. This report presents and describes the final roadmap.

\section{Key Challenges to Health Information Technology Development}

In this section, we briefly describe the key challenges to health IT implementation in Chile that we identified as part of the first phase of this project. These challenges should be addressed in order to achieve the key objectives of the Strategic Program. They can be categorized into four groups, as follows:

- lack of coordination across Chile's dual health care system structure (public and private)

- lack of communications and health IT infrastructure

- lack of coordination across stakeholders

- health IT workforce shortages.

Each of these factors has implications for health IT strategy and the proposed roadmap.

First, the dual health care system structure and health care system reforms implemented in the past ten years allow patients receiving care in the public system to also access care in the private sector. This means that health IT designed and implemented in the public sector must consider the fact that, within the private sector, the National Health Fund (Fondo Nacional de Salud, or FONASA) is another insurance company. As a result, developers of health IT for the public sector should consider interoperability issues with existing health IT systems in private clinics and hospitals. In addition, providers in the public system might not have the technology to access health IT systems. As a result, health IT systems that have as an objective the ability to follow patients between the public and private health care systems should explore the existing private-sector health IT systems in order to identify and resolve any potential interoperability issues for the systems selected for the public sector.

Several issues fall into the second challenge category, which we broadly describe as the lack of health IT infrastructure. Our findings indicate that, at the most immediate level, not all clinics 
and hospitals currently have the basic telecommunications connections necessary to implement health IT projects. Another issue is the lack of system interoperability, such that different hospitals have different health IT systems that cannot communicate with each other. Lack of digital literacy is also a concern for the potential users of health IT products - both providers and patients. Finally, simply adopting a new health IT product does not guarantee successful implementation; workflow disruption can lead to poor execution and reduce the usefulness of the product. Some potential solutions to these specific challenges include information technology (IT) infrastructure improvements and change-management training in advance of health IT implementation.

A third key challenge is the lack of coordination across key stakeholders, including different government ministries involved in developing the health IT sector (for example, the Ministry of Economy, Development and Tourism; Ministry of Health [Ministerio de Salud, or MINSAL]; and Ministry of Finance), health IT companies, and the public and private health care delivery systems. This was especially highlighted in interviews. The results of the lack of coordination include poorly defined objectives and priorities, weak system interoperability, and disjointed project implementations. Some potential steps to reduce this lack of coordination include defining common goals, assigning specific responsibilities to each stakeholder, and defining mutual stakeholders' benefits.

The final challenge is the lack of health IT workforce to support health IT projects in Chile. The effect of such a shortage is the inability to develop and implement new projects, as well as a lack of evaluation of the costs, benefits, and the value of potential projects. Some potential steps that could help address this challenge include increasing the availability of courses and practical training in health IT, as well as new graduate programs focused on training health IT specialists. We understand from the briefing feedback that a master's program focused on health IT has already been started at the University of Chile.

\section{Methods}

\section{Environmental Scan and Key Informant Interviews}

This project had two phases. First, we researched information about current health IT projects operating in Chile and assessed the strengths and weaknesses of the health care system, with a focus on identifying opportunities and challenges for the development of the health IT sector over the short (one to two years), medium (four to six years), and long (ten years) terms. The final report for phase I, Taylor et al., 2016, presents in detail the methods used as part of this work. In short, we conducted an environmental scan of the available literature, including published academic literature, the gray literature, and government and nongovernmental organizations' websites. We then conducted ten key informant interviews with two groups of respondents: Chilean health policy and health IT experts and policymakers (seven interviews) 
and leaders of health IT projects that the Ministry of Economy, Development and Tourism currently funds (three interviews). The first report describes the findings from the environmental scan and key informant interviews.

\section{Designing the Roadmap}

The second phase involved the design of the roadmap. Using the results from the environmental scan and key informant interviews, on January 12, 2016, we presented initial findings in a briefing for the board of directors responsible for the development and approval of the roadmap. The board includes representatives from the Ministry of Economy, Development and Tourism; MINSAL; the Ministry of Finance; the health IT industry; and a patient-advocacy organization. The briefing was designed to present our findings to date and to elicit feedback on the proposed approach for developing the roadmap. Informed by our background research and feedback from the briefing, we developed a roadmap for the development of health IT in Chile that (1) seeks to address key challenges identified as part of the background research, (2) presents objectives for the Strategic Program that reflect stakeholder feedback received as part of the briefing, (3) describes activities to achieve each objective, and (4) presents examples of incentive programs from other countries that can serve as models to encourage the development of health IT in Chile.

Figure 1.1 shows the conceptual model underlying the design of the roadmap. We first identified the key inputs and activities needed to successfully implement the project objectives and the changes and outcomes that might arise from the project. We consider two stages to the overall effort to expand the implementation and use of health IT in the public sector in Chile. The first stage, which is the focus of this roadmap, is the Strategic Program, and the second stage focuses on the potential changes and outcomes that could arise from the successful implementation of the Strategic Program. We discuss specific aspects of each stage below. 
Figure 1.1. Conceptual Model for Designing the Roadmap

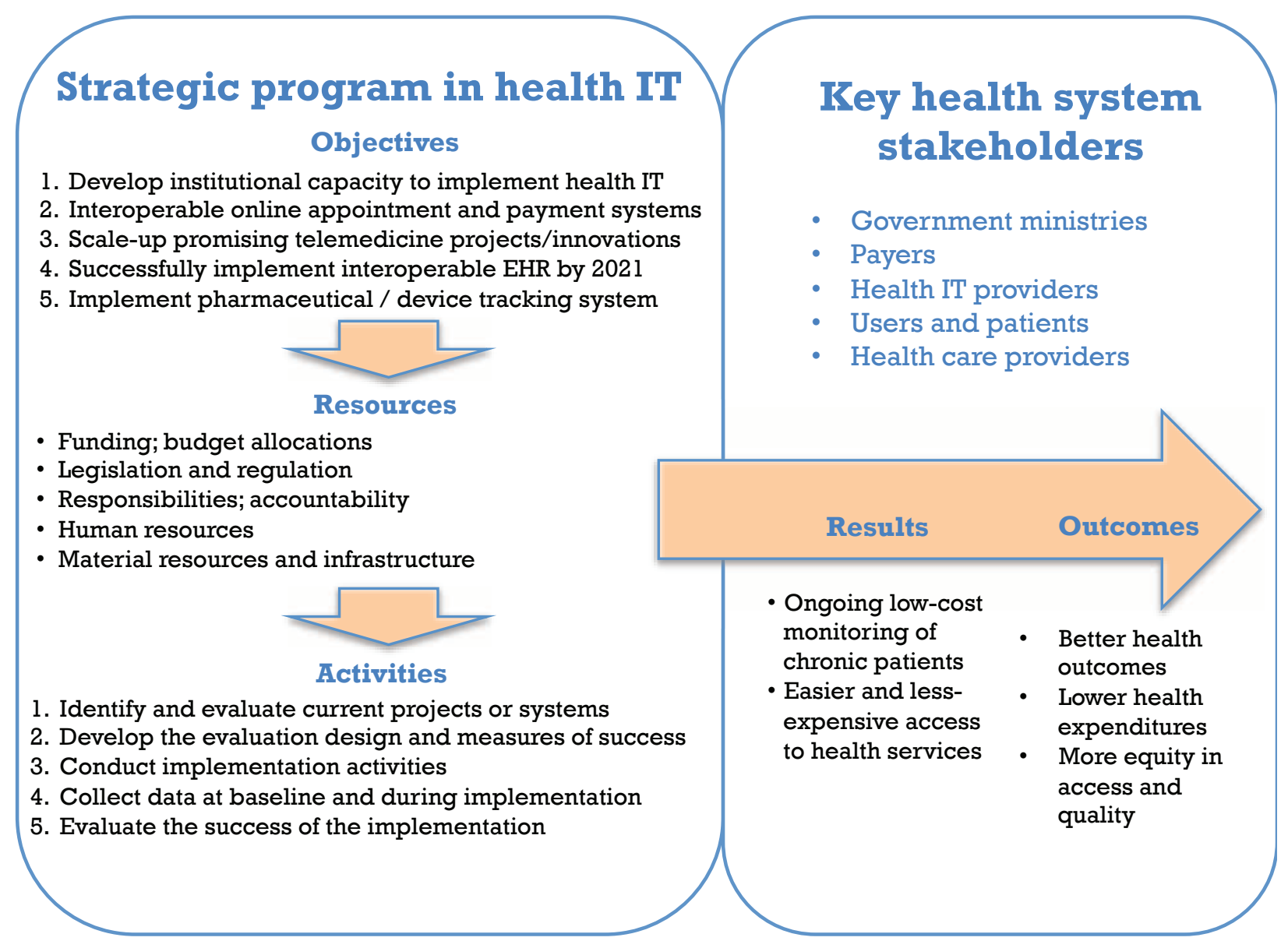

NOTE: EHR = electronic health record.

\section{Strategic Program Stage}

The Strategic Program stage is divided into three key categories: first, identification of the objectives the roadmap intends to achieve; second, assessment and gathering of the resources needed to accomplish the objectives for the roadmap; and third, undertaking the tasks or activities that must be undertaken and completed to achieve the objectives. Our approach was to first define the objectives and then identify the resources and activities needed to achieve each objective.

To facilitate the implementation of the roadmap activities, several resources must be made accessible or developed. One resource is funding, which will most likely be in the form of budget allocations from the government to purchase specific projects or materials, as well as funding designated for key stakeholders working to accomplish the specific activity. Another resource is human capital, which focuses on one of the challenges identified as part of the environmental scan and interviews. To successfully implement health IT projects in different health care settings, specialists in health IT will be needed. In addition, health services employees (e.g., 
physicians, nurses, and administrative staff) will need to be trained in the use of any new health IT product. Finally, human capital can also include the participants in work groups or task forces designed to flesh out the specifics for a given activity included as part of the roadmap.

Another important resource is the material resources and infrastructure needed to implement health IT products in a given setting. These material resources can include telecommunications connectivity, hardware and software, and mobile devices. Telecommunications connectivity materials include the infrastructure (e.g., telephone poles, Internet wiring) necessary to connect health care institutions and patients to the newly adopted health IT projects. Hardware and software include all of the necessary materials required to implement a given project. Mobile devices could help connect physicians and patients.

Finally, as highlighted during the briefing in January, one important input to the project will be a review of existing legislation and regulations and the implementation of any changes necessary to successfully achieve the roadmap objectives. These changes might be needed to create incentives for the development of health IT projects but might also serve to remove obstacles currently in place that restrict key stakeholders' ability to assess health IT projects and successfully implement them. In addition, some laws or regulations might need to be clarified. As part of the key informant interviews, we heard that the question of data ownership was an important challenge to health IT implementation. More specifically, respondents indicated that health IT companies included clauses in their contracts specifying that the company owns the data resulting from health IT products. During the briefing, attendees discussed the fact that, although there is a law in place that prohibits this, it still occurs in practice. Changes to the law or better enforcement is needed to ensure that MINSAL and others measuring the success of the roadmap objectives have access to the necessary data in order to conduct the evaluation.

Using lessons learned from the environmental scan, key informant interviews, and the briefing, we drafted a set of proposed objectives based on feedback from the briefing and edited them based on feedback from the client. We then identified the key activities needed to accomplish each objective.

In Chapter Two, we describe the key activities and their associated objectives in detail. In brief, the activities fall into three key categories: (1) preparation for implementation, (2) implementation, and (3) evaluation. The preparation step includes establishing criteria for selecting a given health IT project, evaluating current health IT projects for quality and value, and establishing incentive programs to encourage care providers and patients to adopt technology. Implementation includes all activities related to incorporating the health IT project into a given health care setting. Evaluating the success of the objective includes establishing measures of success, collecting data, designing the evaluation study (if necessary), and conducting the evaluation. 


\section{Results and Outcomes}

Although this project focuses on the development of the Strategic Program, and the measures of success described in this report are focused on achieving the specific objectives outlined in Chapter Three, it is also important to consider the broader health care system and economic effects of this roadmap. The activities undertaken as part of this roadmap will affect health care system stakeholders, including the health IT industry, providers, and patients. The outcomes can fall into two categories: first, the results or short-term changes, and second, outcomes or broad effects on welfare.

Health IT implementation could have broad effects on the public health care system in Chile, although these impacts might vary based on the level of success of the implementation efforts and the extent to which health IT products do, in fact, result in anticipated changes. Some specific effects might include reduced spending, increased access to care in the public system, and increased quality of care provided. Other outcomes might include improvements in care for patients with chronic conditions and increased equity in the delivery of care.

\section{Organization of This Report}

This report has four chapters. Chapter Two presents the roadmap, which is organized into separate objectives and the activities necessary to achieve each objective. Chapter Three describes some of the incentive programs that might be used to help ensure the success of the objectives that focus on adoption and successful implementation of health IT projects. Chapter Four presents conclusions, including the limitations associated with this project and the key recommendations related to the implementation of the roadmap. 


\section{Chapter Two. A Roadmap to Foster the Development of Health Information Technology}

This chapter presents the five objectives of the roadmap, as well as the specific activities necessary to achieve each objective. Figure 2.1 outlines the objectives for the roadmap. The overall goal of the project is to expand health IT utilization in order to improve health system operations, reduce costs, and improve health outcomes. This goal fits with the conceptual model in considering the eventual health system effects of health IT expansion in Chile.

Figure 2.1. Key Objectives of the Health Information Technology Roadmap
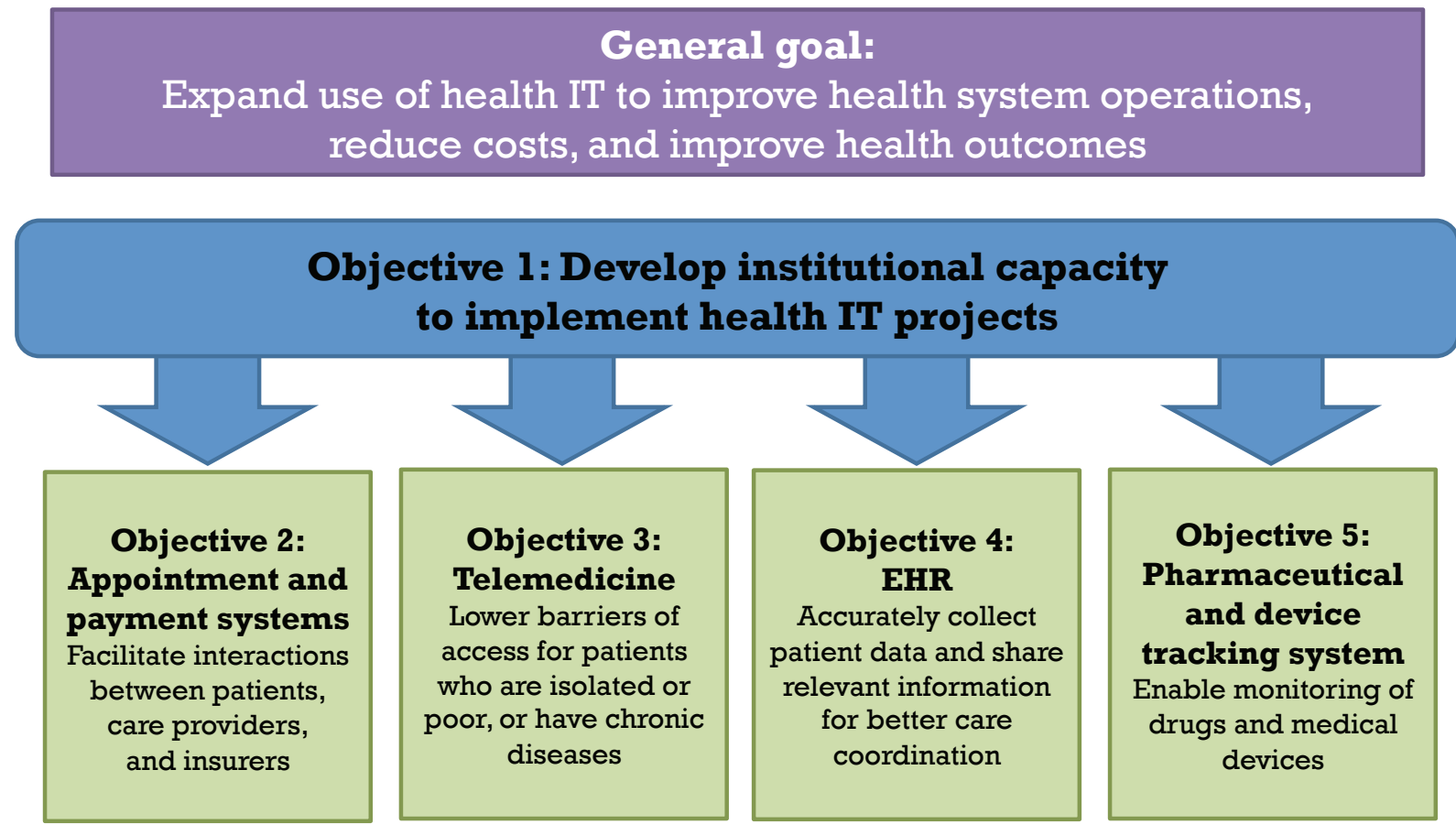

The first objective described in detail in this chapter is to develop institutional capacity to implement and monitor health IT projects. This objective focuses on the creation of an oversight institution whose primary purpose is to oversee the activities necessary to achieve all of the roadmap objectives. Below this objective, which is a necessary condition for successfully 
achieving the other objectives, are four health IT-specific categories, each of which has an associated objective as part of the roadmap. We also present here the specific benefits that each health IT category offers.

Figure 2.2 presents the suggested timeline for achieving the five specific roadmap objectives. Activities for the first objective run through the entire term of the roadmap (i.e., the coming ten years), while activities included as part of the other four objectives have varying lengths based on our recommendation as to the length of time necessary to conduct the key activities for each objective.

Figure 2.2. Timeline for Achieving Roadmap Objectives

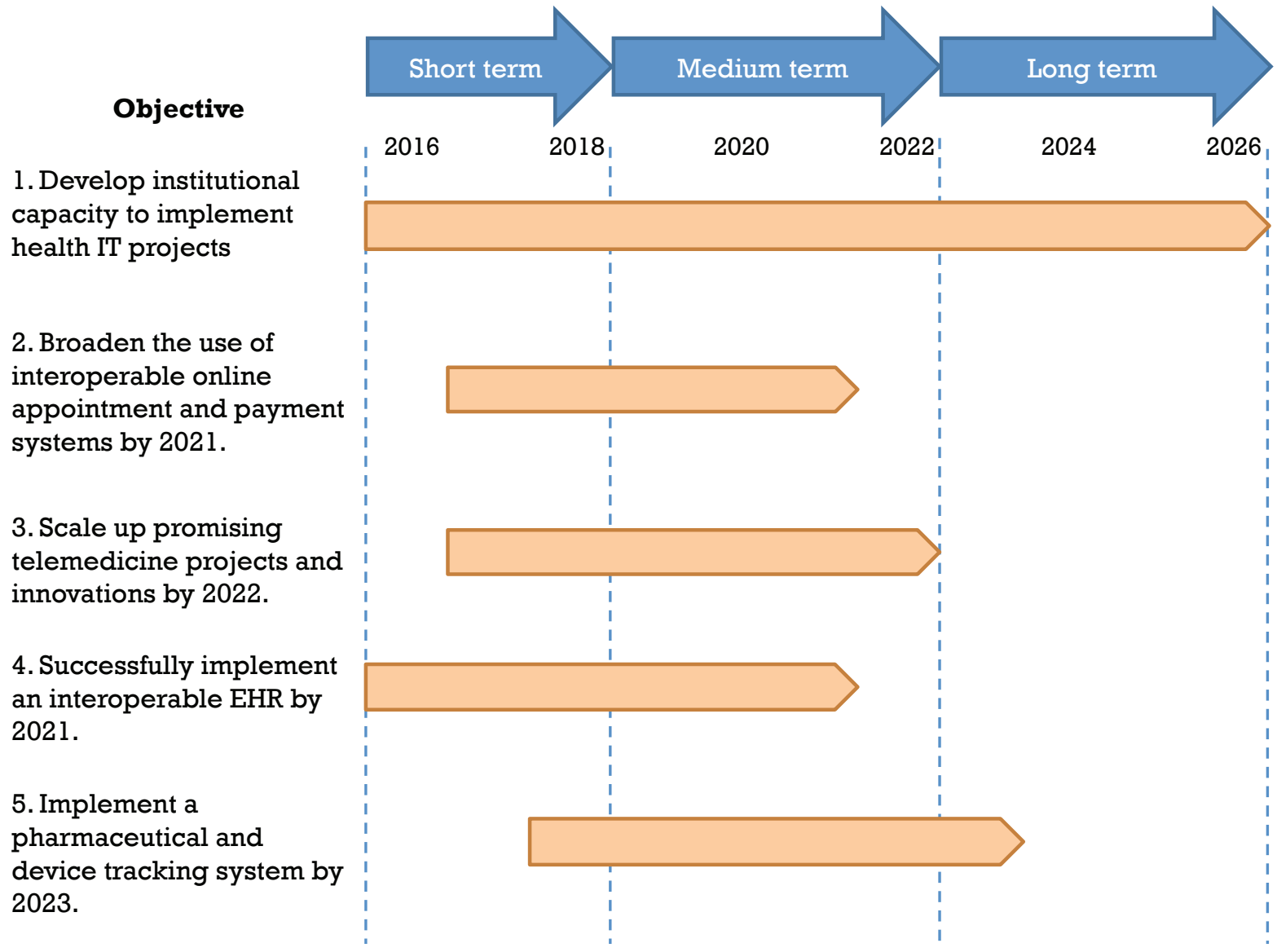

We describe the timeline and key activities in detail for each objective below. For objectives 2 through 5, five broad implementation and evaluation steps must occur to achieve each objective:

1. Identify and evaluate current projects and health IT systems relevant to the specific objective. This activity relies on the premise that allocation of public resources for largescale interventions is ideally based on the interventions' expected benefits and costs. For 
medical interventions in particular, safety and effectiveness must be demonstrated before the intervention is approved for regular and large-scale use.

2. Develop the evaluation design and measures of success. The main objectives result in either expansion of existing health IT products or implementations of new products, and it will be important to evaluate the extent to which the objective has been met. Evaluation of the success of each objective will enable the oversight institution to illustrate to funders, policymakers, and stakeholders the extent to which the roadmap has achieved its goals, which in turn can affect future resources, improve decisionmaking related to the health care system, and help identify how and whether to encourage broader technology adoption. In addition, designing the evaluation prior to implementation activities allows for midcourse corrections that could improve the likelihood of implementation success.

3. Conduct implementation activities. The implementation activities include scale-up of existing products or implementation of newly evaluated and certified health IT products, such as EHRs. Implementation activities will vary by objective, but, in general, we propose selection of specific hospitals and clinics for scale-up and implementation based on criteria, including whether the hospital has the infrastructure necessary to adopt the product, the level of the hospital's interest in adoption, and an estimate of the implementation's effect on end users.

4. Collect data at baseline and during implementation activities. It will be important to collect data to measure the success of the implementation both prior to the start of implementation activities and throughout the implementation. This will enable the oversight organization we propose as part of objective 1 to review the success of the implementation as it occurs, in order to make any changes that might help improve the likelihood of success.

5. Evaluate the success of the implementation. Using measures of success determined as part of step 2, we recommend that the last broad activity be to evaluate the extent to which the objective was achieved. The evaluation will help to show whether funding and other resources expended on the implementation efforts, and the roadmap more broadly, led to successful changes in health IT implementation and utilization in Chile.

For each objective ( 2 through 5) below, we describe how each of these general implementation and evaluation steps could be operationalized to apply to the specific objective and health IT type.

\section{Objective 1: Develop Institutional Capacity to Facilitate and Monitor the Implementation of the Roadmap}

The first objective is to develop the institutional resources necessary to facilitate and monitor the activities designed to meet the other four objectives. An important set of activities within the roadmap is that of assessing the resources necessary to meet the project objectives. This objective describes specific activities related to identification of these resources.

Figure 2.3 illustrates the timeline for starting and completing each of the key activities associated with objective 1 . The activities generally begin immediately, and the oversight of the 
implementation activities continues throughout the period of the roadmap. We describe each activity in more detail in the sections below.

Figure 2.3. Timeline for Key Activities to Achieve Objective 1

\section{Objective 1: Develop institutional capacity to implement health IT projects in the health system}

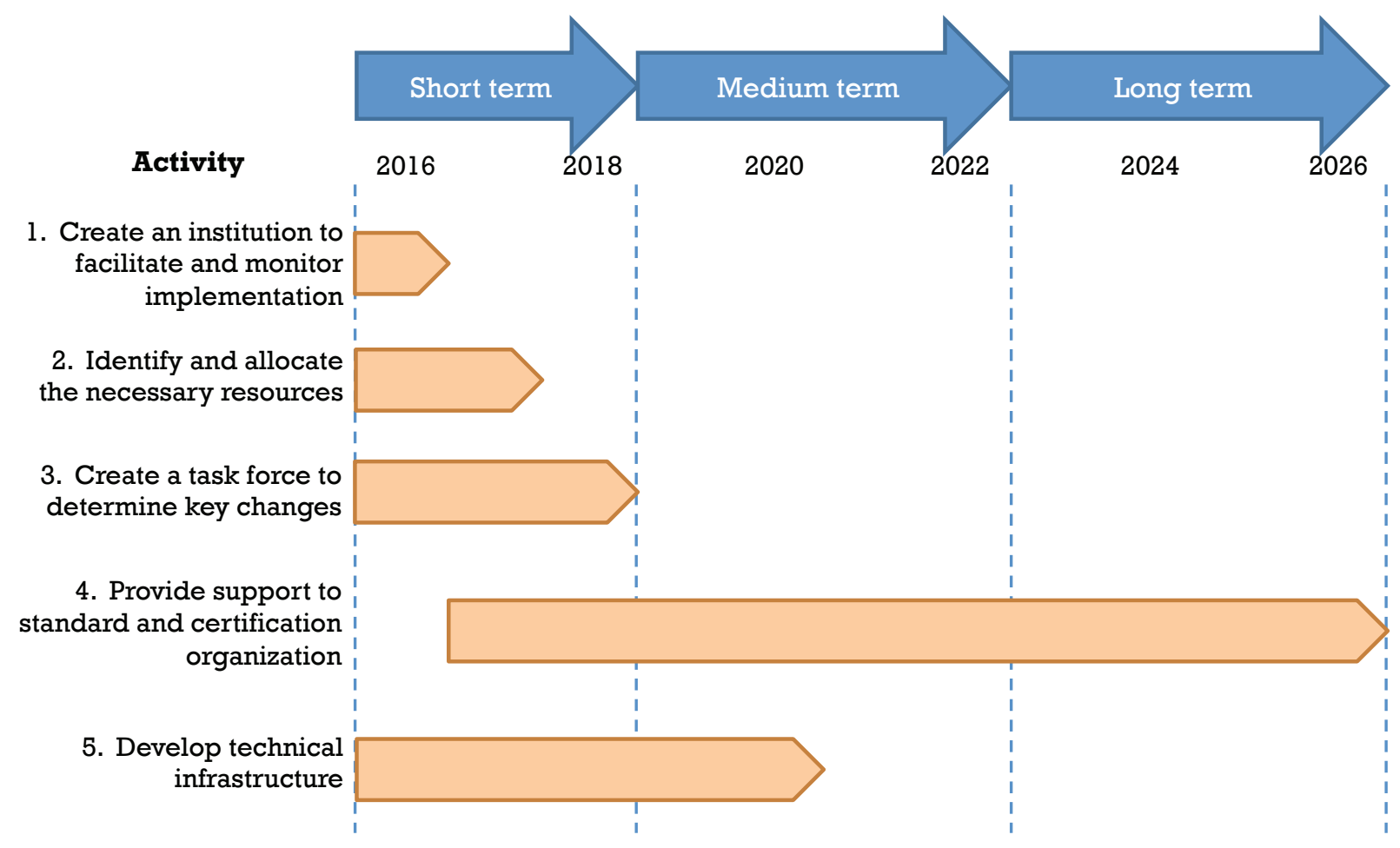

\section{Create an Institution to Facilitate and Monitor Implementation}

As part of the environmental scan and key informant interviews, we identified lack of stakeholder coordination as a key challenge to the successful growth of health IT in Chile. To address this challenge, the first activity within objective 1 is to create an institution whose purpose is to facilitate and monitor the implementation of the roadmap. This institution would ideally be independent of the government, with a separate board of governors and the possibility of receiving funding from outside private donors. However, the primary funding stream would likely be the government. Because government administrations are in office for only four-year terms, independent leadership of an oversight body would enable the institution to focus on the long-term objectives and changes necessary to achieve those objectives, without being concerned about short-term changes within a given governmental administration. (Of note is the fact that an organization called Salud + Desarrollo [Health and Development] has already been created. This 
organization is intended to serve as the overseer for activities related to the broad Health and Development Strategic Program and will likely serve the role described as part of this activity.)

\section{Identify and Allocate the Resources Necessary to Accomplish Roadmap Activities}

The newly created institution should first identify the specific resources needed to accomplish the other roadmap activities. These resources will include not just the costs associated with a given objective but also human capital and material resources. We have begun to identify these resources as part of the conceptual model, but a detailed review and analysis were beyond the scope of this project and are instead an activity for the IT coordination institution. In addition, the Ministry of Economy, Development and Tourism has already begun to identify specific ministry-funded projects that could help to achieve some of the activities and objectives as part of the roadmap. For example, ministry-funded projects include those related to data mining and collection, as well as others focused on the development of human capital and fostering research and development in order to encourage growth in health IT. Further examination of these projects and their potential application to the roadmap activities should be conducted during the early phases of the roadmap.

\section{Create a Task Force to Determine Key Changes Necessary to Foster Health Information Technology Growth}

One important piece of feedback from the briefing is that the oversight institution might need to consider important policy and program changes in order to facilitate the successful implementation of the roadmap objectives. To facilitate the identification of these key changes, the third activity for the institution should be to create a task force to address these issues. The task force should be composed of representatives from all of the key stakeholders in health IT in Chile. These key stakeholders were identified as part of the environmental scan and key informant interviews and include government ministries, academic institutions, health IT industry, providers, and patients.

The task force could address four key areas:

- key law and regulatory changes necessary to foster health IT growth

- incentives designed to encourage the growth of research and development in health IT

- incentives designed to encourage the growth of human capital

- the interaction between public and private providers.

Each of these areas is essential to the successful completion of the other four objectives within the roadmap, and each was highlighted as part of the first phase of this project as important areas to address. More information can be found as part of Taylor et al., 2016, but we highlight possible approaches to these areas here.

One important legal area is privacy law. Electronic data not only provide patients with a fast route to access their medical records but also raise patient-privacy issues. The oversight 
institution should explore whether new laws should be put in place to require security to protect the new data to be created as part of this project, to limit access, and to ensure that patients have access to their own data. Legislation could also ensure that patients are informed about how their data will and will not be used, inform them of their rights and how to file complaints when their privacy has been compromised, and define the means by which the laws will be enforced.

To provide a foundation for discussing possible privacy law approaches, we briefly explored how different countries have approached this question. The European Union (EU) relies on an overarching data privacy law (EU Directive 95/46/EC [EU, 1995]), as well as Directive 2002/58/EC (EU, 2002), which focuses on privacy and electronic communications. This law governs all personal data, not just medical data, while the United States has a healthspecific law, the Health Insurance Portability and Accountability Act of 1996 (Pub. L. 104-191), which, among other things, addresses medical data protection. This 1996 law was supplemented by associated privacy and security rules that describe in detail how patient data are to be protected. The oversight institution should consider these laws in depth and determine which, if any, aspects of the laws might apply to Chile.

Possible approaches for encouraging research and development of new health IT products and services include grants, subsidies, taxes, and other incentives designed to foster growth of the sector within Chile. Another alternative could be a contest to identify projects with high potential for success or that target certain populations (e.g., patients in lower socioeconomic groups). AccuHealth, a telemedicine project currently in operation in Chile, was one of the awardees of a similar contest run by the United Nations (Global Growth Markets, 2015).

As mentioned in the environmental scan, part of the U.S. program to improve health IT involved addressing the shortage of staff. This was achieved via a program that created four interrelated programs seeking to increase the number of health IT professionals, including the development of a curriculum and supporting resources, the establishment of training programs, and the creation of national competency exams (Mathematica Policy Research \& Harvard School of Public Health, 2015). This program increased enrollment in health IT programs, and, as of 2014, 63 of 81 community college programs were still in place despite the end of government funding (NORC at the University of Chicago, 2014). Chile could consider creating and subsidizing similar training programs to facilitate growth of the health IT workforce.

In the environmental scan and interviews, the interaction between public and private providers was identified as a key challenge. Private providers are part of a fairly advanced network that largely uses health IT, while public providers might not have access to the technology at this point in time. The oversight institution should explore the successes and failures of the private system and determine whether adaptation of the private provider systems for the public sector might be an appropriate approach in order to make the records for patients using both public and private systems accessible in both systems. 


\section{Provide Support to the Standard and Certification Organization}

The Ministry of Economy, Development and Tourism has already worked to establish an organization whose purpose is to promulgate the standards necessary to allow for interoperability between different health IT systems. It will be important going forward for the oversight institution to maintain support for this organization and to ensure that standards are determined and issued. The standard organization might also provide evaluations and certification of the various health IT products available in the Chilean market. During our interviews, we heard that it can be difficult to confirm the quality and value of a given product available on the market; conducting evaluations of the available (and newly created) products and certifying the ones that meet a series of established criteria could help reduce end users' concerns regarding the relative quality of one product versus another.

\section{Develop Technical Infrastructure}

One key challenge we identified as part of the background research is the lack of infrastructure for Internet connectivity. This must be built for the $30 \%$ of hospitals that currently have no access (according to our interviews), as well as for rural providers in clinics and elsewhere, in order for the system to effectively connect and coordinate care. Hospitals and clinics with limited or no Internet access should first be identified. Among those, hospitals and clinics interested in adopting health IT systems should be prioritized for Internet connectivity, with a goal of connecting all provider locations. This activity will likely require the cooperation and participation of the Ministry of Transportation and Communications, which directs activities related to telecommunications infrastructure development.

\section{Objective 2: Successfully Implement and Broaden the Use of an Interoperable Online Appointment, Referral, Medical Leave, and Integrated Payment System by 2021}

The second objective focuses on strengthening the existing appointment, referral, medical leave, and payment systems over the short and medium terms. By scaling up the adoption and use of these types of health IT systems in the public health care system, Chile can work to address the problems of long waiting times and overutilization of public hospitals and emergency care. Figure 2.4 illustrates the proposed timeline for starting and completing the activities associated with objective 2 . 
Figure 2.4. Timeline for Key Activities to Achieve Objective 2

\section{Objective 2: Broaden the use of interoperable online appointment, referral, medical leave and payment \\ systems by 2021}

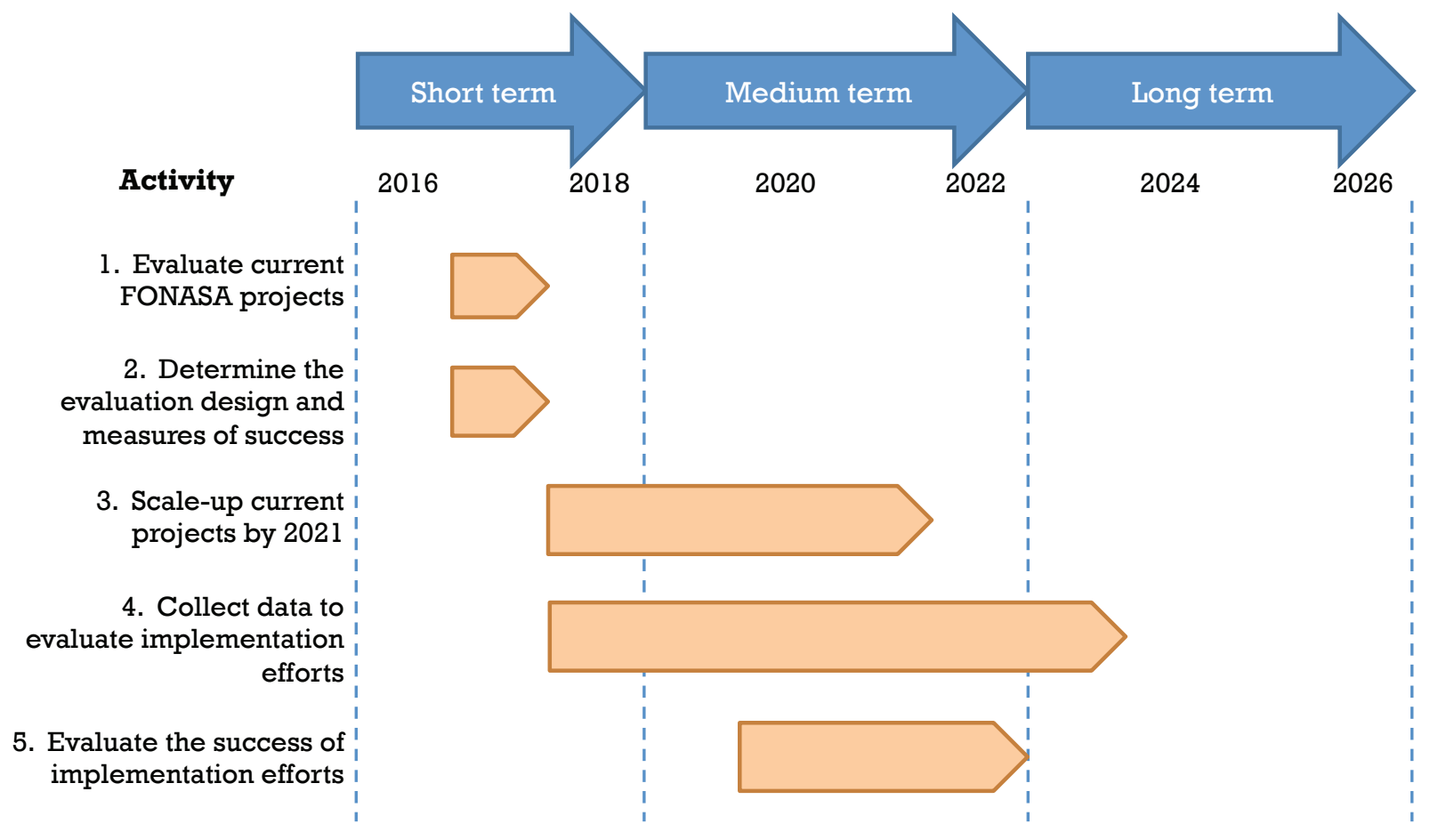

\section{Evaluate Current National Health Fund Projects}

The first key activity for this objective is to evaluate the current status of each of the projects listed in Table 2.1. An evaluation would involve discussions with key stakeholders (e.g., FONASA) and project end users to identify specific challenges associated with the current systems and the potential solutions for each challenge. These challenges can include those related to daily use and impediments in the process between primary care clinics and hospitals across sectors (public versus private). This evaluation should include an estimate of the costs associated with addressing each of the challenges. 
Table 2.1. Current Online Appointment, Referral, Medical Leave, and Payment Systems

\begin{tabular}{|c|c|c|}
\hline Project & Description & Status \\
\hline $\begin{array}{l}\text { Integrated online } \\
\text { appointment, } \\
\text { referral, and } \\
\text { counterreferral } \\
\text { system with } \\
\text { automated } \\
\text { payments }\end{array}$ & $\begin{array}{l}\text { In 2008, MINSAL created a waiting-list } \\
\text { register system together with a referral and } \\
\text { counterreferral system (Capurro, 2007; } \\
\text { Fernández \& Oviedo, 2011). Its aim is to } \\
\text { reduce inefficiencies in scheduling and long } \\
\text { waiting times through decreased hospital } \\
\text { readmissions and utilization of public } \\
\text { hospitals and emergency rooms. FONASA is } \\
\text { coordinating referrals with automated } \\
\text { payments across sectors. }\end{array}$ & $\begin{array}{l}\text { As of } 2013 \text {, the project covered more than } 80 \% \\
\text { of health care providers (MINSAL, 2013). } \\
\text { FONASA facilitates referrals combined with } \\
\text { automated payments across health units, } \\
\text { including privately owned clinics. The process } \\
\text { was improved after collaborations began with } \\
\text { the private sector. An online appointment } \\
\text { system is available via the FONASA website. } \\
\text { No formal assessment is available. }\end{array}$ \\
\hline $\begin{array}{l}\text { Electronic medical } \\
\text { leave system }\end{array}$ & $\begin{array}{l}\text { FONASA has implemented this system } \\
\text { based on a model from and in collaboration } \\
\text { with the Instituciones de Salud Previsional. } \\
\text { This project also connects them to the } \\
\text { Committee on Preventive Medicine and } \\
\text { Disability (Comisión de Medicina Preventiva } \\
\text { e Invalidez), compensation funds, FONASA, } \\
\text { and the Social Security Authority (Asociación } \\
\text { Chilena de Informática en Salud, 2011; } \\
\text { MINSAL, 2013; Pan American Health } \\
\text { Organization \& World Health Organization, } \\
\text { undated). }\end{array}$ & $\begin{array}{l}\text { The pilot project started in November } 2011 \text { and } \\
\text { was followed by a five-month testing phase. It } \\
\text { received the "Best Project of the Year" award } \\
\text { (Pan American Health Organization \& World } \\
\text { Health Organization, undated). To date, more } \\
\text { than } 100,000 \text { electronic medical leaves have } \\
\text { been processed, with processing time } \\
\text { decreasing from } 90 \text { to only } 15 \text { days. This system } \\
\text { serves } 10,000 \text { medical professionals, } \\
8,000 \text { employers, and nearly } 6 \text { million FONASA } \\
\text { patients. Use is currently limited to the Santiago } \\
\text { metropolitan region. The plan is to implement it } \\
\text { in other regions (Pan American Health } \\
\text { Organization \& World Health Organization, } \\
\text { undated). }\end{array}$ \\
\hline $\begin{array}{l}\text { E-vouchers or online } \\
\text { forms to confirm or } \\
\text { change health } \\
\text { insurance coverage } \\
\text { and providers }\end{array}$ & $\begin{array}{l}\text { Automated or electronic services are } \\
\text { available on the FONASA website } \\
\text { (FONASA, 2015). }\end{array}$ & $\begin{array}{l}\text { More than } 200,000 \text { people per month use these } \\
\text { services in person, so moving them online might } \\
\text { reduce waiting time and red tape for both } \\
\text { patients and health care providers (FONASA, } \\
2015) \text {. The same holds for online appointment } \\
\text { systems. }\end{array}$ \\
\hline
\end{tabular}

\section{Determine the Evaluation Design and Measures of Success}

According to the current projects' evaluation results, interviews, and cost estimates, the oversight organization should design a pre-analysis plan for the evaluation of current projects both during and after they are scaled up. Within this activity, the evaluation research design, use and effect of interventions (including incentives for all users, hospitals and clinics on one side and patients on the other), and measures of success should be clearly identified. Some of those measures could include the percentage of clinics or hospitals using each of these systems; increased system use by patients; share of appointments scheduled online; changes in waiting times to see a provider; changes in the number of payment processing days; and reported satisfaction with system use from hospitals, clinics, and patients. Community- or hospital-level workshops for clinical staff and patients on how to use these systems should be planned for evaluation as well. Although FONASA already posts educational videos on its website, the website itself should be advertised at local clinics as an entry point for online appointment systems for patients. 


\section{Scale Up Current Projects by 2021}

To expand the reach of these systems, scale-up should be implemented both in regions around Santiago to reduce challenges in care delivery due to high patient density and in remote areas where travel to health care clinics might be time-consuming and costly. To scale up the use of online appointment systems, advertising the FONASA website to patients, as mentioned above, is one of the first steps. We also suggest increasing utilization of these systems in clinics and hospitals that already have the systems and infrastructure in place but report low use and are interested in increasing their utilization. These hospitals could be identified via interviews with stakeholders and users as part of the first activity, described above. We then suggest reaching out to those with the highest overutilization of services and longest waiting times that are not currently in the system yet have sufficient IT infrastructure to execute a scale-up. Identifying physicians and hospitals outside the system and the level of IT infrastructure in place should follow. Note that it is critical to determine whether and how much investment in IT infrastructure is necessary prior to the start of project implementation. This is a complex task and should be done in collaboration with the Ministry for Transportation and Communications in Chile. Throughout the process of scaling up, communication between key stakeholders, constant activity monitoring, and uptake encouragement will be needed to ensure the success of this activity. Note, however, that these implementation activities should be in line with the evaluation plan so that they do not invalidate its research design.

\section{Collect Data to Evaluate the Success of Implementation Efforts}

To evaluate the implementation efforts in terms of scale-up, it will be important to collect baseline and frequent follow-up data on measures of success, some of which we listed in the sections above. Data collection throughout the scaling-up process is critical. If possible, information obtained from semistructured interviews on users' experiences should be recorded in at least one follow-up survey, in addition to the baseline - in hospitals and clinics in which projects already exist and in which they are planned to be scaled up. Monitoring of data quality is very important, especially focusing on identifying any nonrandom missing values and measurement errors, because they could create biases when evaluating the success of implementation efforts in the next step.

\section{Evaluate the Success of Implementation Efforts}

The methods to be used in collecting and analyzing the data should be selected to best fit the evaluation design but could include both qualitative and quantitative approaches. Data collected should be regularly analyzed (e.g., at least every six months) to identify progress but also to identify errors or bottlenecks in the implementation process and allow for a prompt response in intervention adjustments. For instance, if waiting times do not significantly improve after six months of providing workshops on how to use the online appointment systems and 
advertisements of FONASA website do not increase the web traffic to the online appointment portal, interventions and incentives should be redefined. Additionally, adjustments in interventions and incentives are needed if the number of referrals does not increase over time or if the number of payment processing days does not decrease. Similar approaches hold for other measures of success.

\section{Objective 3: Scale Up Promising Telemedicine Projects That Target Prevention and Treatment of Highly Prevalent Conditions by 2022}

Telemedicine can help address three major challenges in Chilean health care: (1) lack of specialists outside of Santiago, (2) lack of or delayed access to care in remote areas or areas with high patient density, and (3) overutilization of inpatient treatments of chronic diseases. To address these challenges, the third objective is to identify successful telemedicine projects and to work to scale up the adoption and use of those projects by 2022 . Figure 2.5 presents the timeline for starting and completing each of the key activities for objective 3 .

Figure 2.5. Timeline for Key Activities to Achieve Objective 3

\section{Objective 3: Scale up telemedicine projects by 2022}

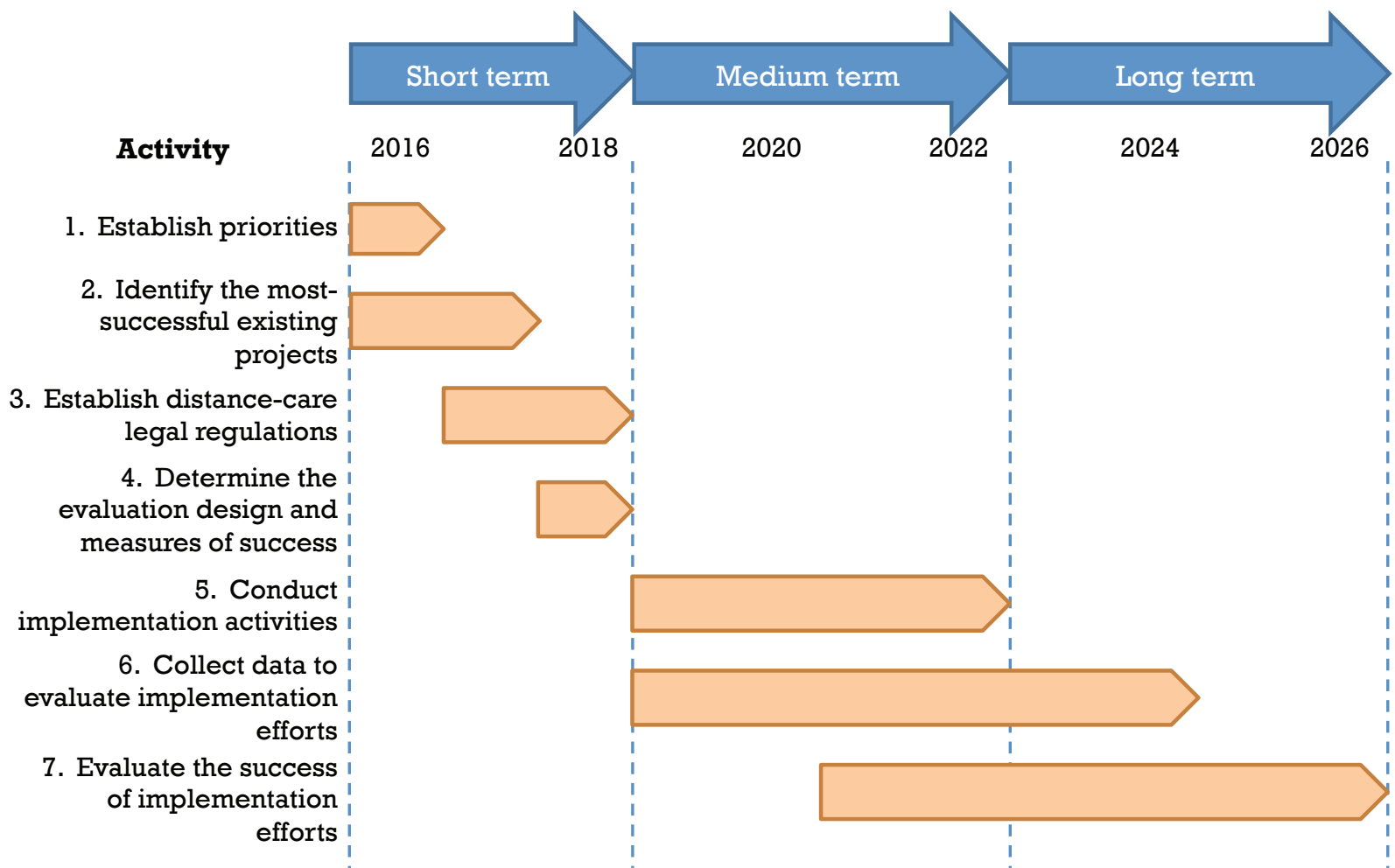




\section{Establish Priorities for Identifying the Highest-Impact Telemedicine Projects}

Prioritized telemedicine projects should primarily fall in the areas of (1) specialties that have longest waitlists, because they are correlated with high prevalence of diseases included in the Acceso Universal con Garantías Explícitas guarantee plan; (2) diseases that can be diagnosed from afar; and (3) situations in which interaction between the specialist and the long-distance operator is relatively simple. Priority should be given to areas with higher density of the disadvantaged population and projects targeting them. Some examples of prioritized projects are those in the field of cardiology or related chronic-disease prevention and their self-management, pathology, dermatology, radiology, or oncology (according to three interviewed stakeholders).

\section{Identify the Most-Successful Existing Telemedicine Projects Through Rigorous Evaluation}

The first activity is to evaluate existing telemedicine projects. Table 2.2 describes four telemedicine projects we identified as the initial pool of projects for the evaluation.

Table 2.2. Current Telemedicine Projects

\begin{tabular}{|c|c|c|}
\hline Project & Description & Status \\
\hline TTECG & $\begin{array}{l}\text { The project provides direct transmission } \\
\text { of electrocardiography and patient } \\
\text { information (e.g., age, sex, medical } \\
\text { history) by telephone between primary } \\
\text { health care centers in distant areas and a } \\
\text { centralized facility in Santiago with } \\
\text { cardiologists }\end{array}$ & $\begin{array}{l}\text { More than } 523,371 \text { TTECGs have been transmitted } \\
\text { and interpreted. Descriptive evidence suggests a } \\
\text { decreased diagnosis of and hospital mortality due } \\
\text { to myocardial infarction after TTECG } \\
\text { implementation (Toledo, Roca, Antón, Martin de } \\
\text { Nicolás, Varela, et al., 1989). No formal } \\
\text { assessment is available. }\end{array}$ \\
\hline AccuHealth & $\begin{array}{l}\text { This remote monitoring system for } \\
\text { patients suffering from chronic diabetes } \\
\text { and cardiovascular problems promotes } \\
\text { patient self-care, potentially reducing } \\
\text { consultation services for unscheduled } \\
\text { hospitalizations. }\end{array}$ & $\begin{array}{l}\text { The initiative began in } 2014 \text { to serve } 2,000 \text { low- } \\
\text { income patients insured under FONASA across } \\
\text { eight centers in Santiago. AccuHealth aims to } \\
\text { serve } 200,000 \text { chronically ill in Chile's public health } \\
\text { system by } 2020 \text { (FONASA, 2014). No formal } \\
\text { assessment is available. }\end{array}$ \\
\hline $\begin{array}{l}\text { Diagnóstico } \\
\text { Automatizado de } \\
\text { Retinografías } \\
\text { Telemáticas }\end{array}$ & $\begin{array}{l}\text { This project detects diabetes retinopathy } \\
\text { through automatic processing of digital } \\
\text { images and web-based telemedicine. } \\
\text { This allows for early diagnosis and limits } \\
\text { vision loss and blindness. }\end{array}$ & $\begin{array}{l}\text { The company is starting pilot studies and working } \\
\text { to automate diagnostic processes and obtain the } \\
\text { certificates and validations to start using the tool in } \\
\text { practice. No formal assessment is available. }\end{array}$ \\
\hline $\begin{array}{l}\text { Comunicación y } \\
\text { Seguimiento Movil } \\
\text { en Salud model: } \\
\text { mobile health for } \\
\text { type } 2 \text { diabetes }\end{array}$ & $\begin{array}{l}\text { The model supports communication } \\
\text { between professionals in primary health } \\
\text { care centers and their patients to facilitate } \\
\text { self-management, timely diagnosis, and } \\
\text { initiation of treatment for type } 2 \text { diabetes } \\
\text { through mobile phones or emails. It } \\
\text { targets vulnerable populations. }\end{array}$ & $\begin{array}{l}\text { The 13-month pilot study was implemented in } 2013 \\
\text { in two selected health centers in Puente Alto } \\
\text { (Alcayaga, Pérez, Bustamante, Campos, Lange, et } \\
\text { al., 2014). Scale-up has been limited by } \\
\text { (1) incompatibility in phone technology, (2) a } \\
\text { shortage of qualified nurses, and (3) patients' } \\
\text { limited literacy (Piette, Blaya, Lange, and Bru } \\
\text { Sanchis, 2011). No formal assessment is available. }\end{array}$ \\
\hline
\end{tabular}

NOTE: TTECG = transtelephonic electrocardiography. 
An impartial third party should conduct a rigorous evaluation of these four projects, as well as any additional projects that the oversight institution identifies as being potential candidates for scale-up. Evaluations could make use of a variety of methods, including randomized controlled trials or project evaluation using existing data; a mixed-methods approach that incorporates quantitative, as well as qualitative (e.g., interviews), methods; and a cost-benefit analysis of the use of these projects, both in isolation and in comparison to each other. In addition to national grants, funding for these evaluations could be obtained from the National Institutes of Health in the United States; many of its proposals call for evaluations of telemedicine interventions. The standard and certification organization could release the results of these evaluations for use as the basis for identifying one or two of the most-promising projects in order to begin a small-scale expansion of clinics and hospitals where the projects are offered. For example, the projects could be implemented first in hospitals that have been identified as capable (e.g., sufficient health IT infrastructure) and interested in implementing new telemedicine projects. Focusing on areas with significant populations who have difficulty accessing in-person health care services might be another way to focus the scale-up of these projects.

\section{Establish Legal Regulations for Distance Care for Patients and Clinicians}

Legal regulations for distance care must be clearly defined in terms of possible medical errors and the means by which health insurance might pay for this type of service. When federal and state legislation and major insurers increased coverage for distance care in 2011 in the United States, telemedicine practice escalated substantially (GlobalMed, undated). The Federation of State Medical Boards published the Model Policy for the Appropriate Use of Telemedicine Technologies in the Practice of Medicine in 2014, which aims to provide guidance to state medical boards for regulating the use of telemedicine technologies.

\section{Determine the Evaluation Design and Measures of Success}

As with other objectives, defining a rigorous evaluation plan and the measures of success of the objective prior to actual implementation (either scale-up or pilot-study evaluation) is crucial because it will guide the baseline and follow-up data collection and implementation activities and lead to an objective assessment of the project's success. Some of the measures of success in telemedicine projects might include the satisfaction and utilization rates of telecounseling, text messaging, and interactive voice response services; the proportion of patients who received diagnostic confirmation within a recommended time frame; and the clinician's or patient's response to diagnostic information (e.g., in terms of clinic follow-up or medicine adherence). Clinical measures of success should be measured as well: changes in the proportion of patients with newly diagnosed disease (e.g., incidence rate) and changes in biomarkers and other reports on health status. We also recommend collecting provider information and measures of system satisfaction over time. 
Telemedicine is not a separate medical specialty — it is often integrated into existing health care institutions, IT, and clinical care. Therefore, we strongly suggest engagement and communication between key stakeholders, such as MINSAL, Corporación de Fomento de la Producción, board-level managers, and some other local authorities (e.g., community leaders), in addition to clinical staff or end users, throughout the product development and implementation in a project's life cycle already in this stage. The aim should be to clearly identify, or even visibly appoint, a key point of contact, such as a project coordinator, and that person's responsibilities and clearly identify benefits for each collaborator. In addition, short-, medium-, and long-term plans for project evaluation and implementation with well-defined activities and measures of success should be defined in collaboration prior to scaling up. These collaborations are often mentioned as a key factor of a successful telemedicine project implementation (Joseph, West, Shickle, Keen, \& Clamp, 2011). Additionally, commitment of support over a longer period (not limited to short political cycles) is crucial for a sustainable telemedicine implementation on a larger scale (Kodukula \& Nazvia, 2011).

\section{Conduct Implementation Activities}

Once evaluations of existing projects are finalized and pre-analysis plan and measures of success for evaluation of scaled-up projects are identified, the next step is to scale up the mostpromising projects outside of Santiago and in other clinics. One of our interviewees suggested that urban areas of development are around Santiago, Viña-Valparaiso, and Concepcion. We suggest identifying hospitals or clinics with sufficient IT infrastructure in place that show interest in telemedicine tools and starting the process of scaling up telemedicine projects there. For application of telemedicine projects in more-distant and remote areas, it is necessary to assess the status of IT infrastructure prior to the actual implementation.

Throughout the scaling-up process, we recommend investing in workforce training for both clinical staff and patients. Examples of these are workshops at universities (e.g., train clinicians while at school) and local communities (e.g., for patients to be familiar with a distance-care concept, workshops on IT literacy). Additionally, we recommend investing in capacity-building and accredited training programs at hospitals or clinics, which a centralized agency could accredit. Training of end users can be conducted once initial groups of employees at different levels are trained (Kodukula \& Nazvia, 2011).

Although the steps listed above focus mainly on the initial implementation activities, support for the decision to actually use health IT is just as important. See Chapter Four for a discussion of the financial and nonfinancial incentives that might be applied throughout the implementation process in order to increase the likelihood of adoption and successful implementation.

\section{Collect Data to Measure the Success of Implementation Efforts}

The independent oversight institution or organization conducting the evaluation should create specifications and select the appropriate types of data to collect in order to measure the success 
of the implementation efforts. These data should be collected both at baseline (before implementation begins) and at frequent intervals throughout the implementation process. Because of the nature of telemedicine projects, much of the data will be collected electronically in real time and can include some of the following types of information: length of time for consultation, type of consultation, whether a diagnosis was given and the basis for the diagnosis (e.g., transmission of test results or other information), whether the patient had follow-up care at a clinic, and the costs associated with the telemedicine visit. These data should be complemented with semistructured interviews on patients' or clinicians' experiences with the product.

\section{Evaluate the Success of Implementation Efforts}

Consistently with what we suggested for the evaluation of FONASA projects, we suggest regular analysis of the collected data (e.g., at least every six months) to identify progress but also to identify errors or issues with the implementation process. As mentioned previously, qualitative and quantitative methods should be used. This will allow for a prompt response in redesigning interventions, such as incentives, and in redefining short-, medium-, and long-term plans.

\section{Objective 4: Successfully Implement an Interoperable Electronic Health Record in the Public Health Care System by 2021}

The president of Chile has established the implementation of an interoperable EHR as a goal for 2020. This roadmap allows for one additional year to achieve this goal. Implementation would have many positive effects, including allowing doctors to access charts remotely, allowing access to multiple providers at once, ensuring backups of important data, and improving legibility and searchability of medical records. EHRs also allow for clinical decision support to automate alerting of critical lab values, potential medication errors, and clinical guidelines and can facilitate direct communication with patients (HealthIT.gov, 2015b). On a population level, electronic data enable better public health data collection and measurement of quality metrics. We lay out some steps that will be needed for successful implementation of an interoperable EHR in the public health care system by 2021. Figure 2.6 illustrates the timeline for the activities needed to complete objective 4 successfully. 
Figure 2.6. Timeline for Key Activities to Achieve Objective 4

\section{Objective 4: Successfully implement an interoperable EHR in the public health care system by 2021}

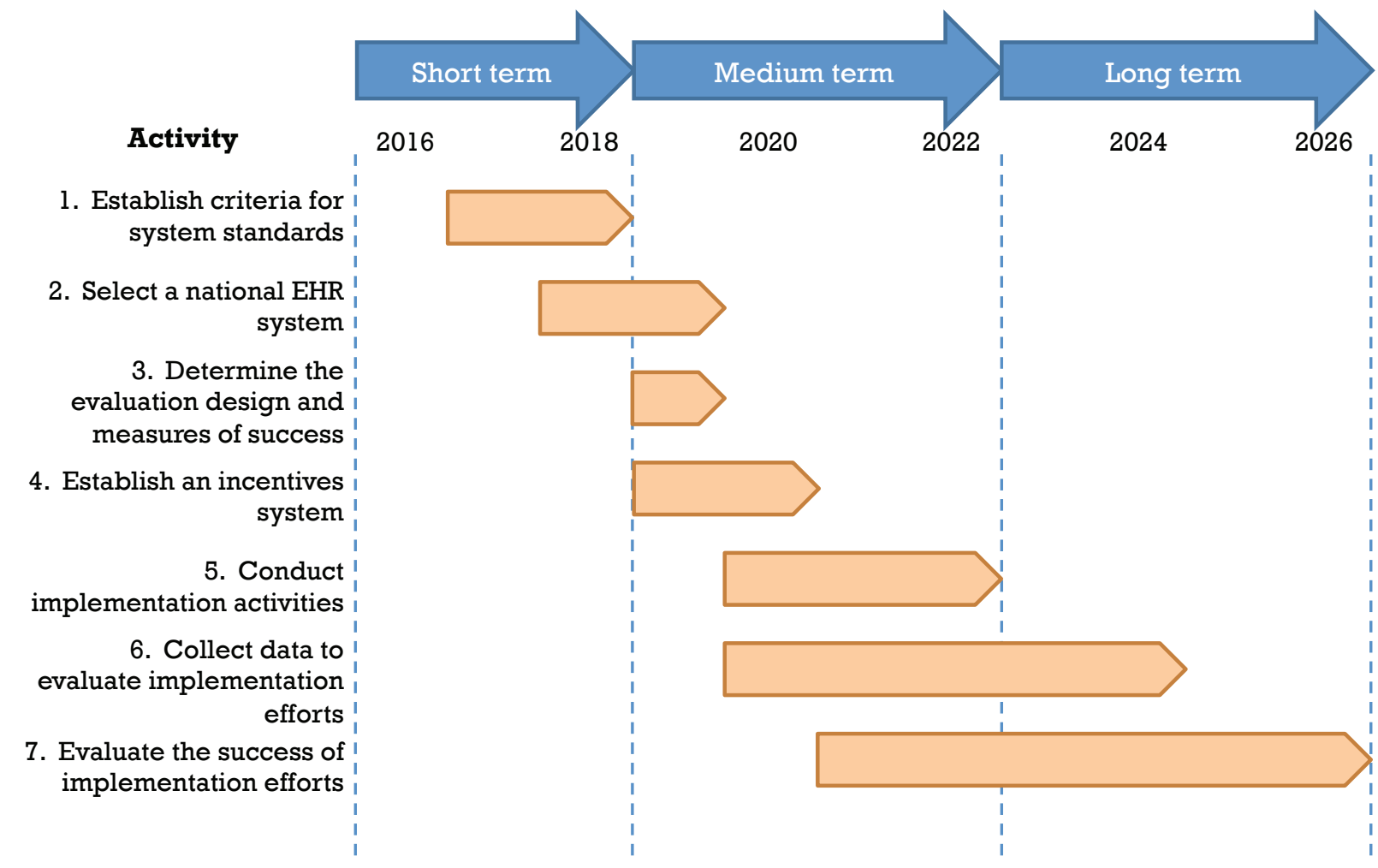

\section{Establish Criteria for System Standards and Interoperability}

Interoperability refers to the potential to share data within different departments in a given institution, as well as an attribute of software that allows the information to flow across the health care system. According to the Office of the National Coordinator for Health Information Technology (ONC), "EHR Interoperability enables better workflows and reduced ambiguity, and allows data transfer among EHR systems and health care stakeholders" (HealthIT.gov, 2013). Because different types of providers often use different systems, from outpatient clinics to intensive care units and from surgery to primary care, interoperability relies on the determination of standards for data transmission, such as for e-prescribing, messaging, and health information exchange, as well as integration with consumer tools, such as personal health records and mobile devices. Two examples of health care data standards that have been adopted in the United States are Health Level Seven International and Fast Healthcare Interoperability Resources (Health Level Seven International, 2015), but their application in specific contexts still requires decisionmaking and customization. 
Standards are also needed for terminology so that the same medication or the same disease will receive the same code and can be interpreted in the same way regardless of the institution or location delivering a service. Multiple databases and ontologies have been established in different languages and different countries, such as the International Classification of Diseases (ICD) from the World Health Organization (World Health Organization, undated). Virtually every U.S. payer, with Medicare leading the way, just upgraded to the tenth edition (ICD-10), while ICD-11 is going to be released in 2018. Multiple systems exist for categorizing medical procedures, medications, and other terminologies. Selection of and determining interaction between these databases is a complex and important decision, and we recommend that the standard and certification organization begin the process of selecting these standards immediately.

\section{Select an Electronic Health Record}

Once standards have been determined, Chile might choose an EHR product that will be the single EHR in use in the public system. There are many ways to select the system and a variety of contracting mechanisms. For example, Chile might choose to select a single vendor to address all of its electronic record needs, or it might focus on criteria and standards that any adopted system must meet. The advantage of selecting a single product is that it makes interoperability much easier and does not require providers to choose among different software and hardware vendors. One way to select a single national vendor would be to implement a public bidding process with a single vendor selected, although, again, there are multiple kinds of contracts that could be considered.

There are some potentially negative repercussions of selecting a single vendor. These include the creation of a monopoly that the selected single vendor holds, which risks limiting competition on prices and innovation. The key trade-off is the fact that applying standards and ensuring that participants meet criteria for adoption, implementation, and use of the EHR are both much easier with a single vendor. In a system in which multiple vendors offer a product designed to meet the specified standards, interoperability standards and software components would need to be clearly described.

An intermediate option is choosing two to five options for software, which allows for some competition between vendors and some choice for consumers while limiting the number of programs that would need to be coordinated for interoperability. As noted in Chapter One, the approach for selecting a vendor or multiple vendors should take into account the current use of EHRs in the private sector in Chile. To the extent that the public system has private and public system interoperability as a goal, compatibility with current EHR systems in the private sector is an important consideration.

Whether Chile selects a single vendor or multiple options, there will be certain stages of implementation. Rollout would begin in a limited number of sites, with scale-up and expansion 
carefully coordinated by the oversight body. Certain regions would be targeted to be first for implementation, with the rest of the country following.

\section{Determine the Evaluation Design and Measures of Success}

Chile's new oversight organization should design an evaluation approach to assess the success of the efforts to scale up the EHR implementation. As with any rigorous evaluation, the evaluation design and major outcomes to be measured should be determined in advance of implementing the scale-up. Potential measures of successful implementation include the percentage of hospitals in the public system that do adopt the EHR by a certain date, the percentage of public hospitals that implement an EHR in specific departments (for example, the emergency department), and the number or percentage of departments and hospitals that meet interoperability standards and are able to share data.

\section{Establish an Incentive System to Encourage Adoption and Successful Implementation}

An important aspect of implementation is the design of incentives intended to motivate potential EHR users to adopt and use the new EHR. As we have reported before, as of 2013, fewer than 20\% of medical records in Chile were digital (MINSAL, 2013). Major barriers to adoption of an EHR include regional variation in computer literacy and facility availability, privacy concerns, and lack of interoperability. The implementation process can also face the challenges of high costs and initially decreased productivity, even if later cost savings are realized. Sistemas de Información de la Red Asistencial has already been taking steps to incentivize adoption, including setting up a certification program for performance. Other types of incentives are possible, including those with and without financial rewards. We describe these possible incentives in greater detail in Chapter Four. One activity the oversight institution should undertake prior to implementation of the new EHR is to select an incentive system and describe the details of the incentive system to potential users.

\section{Conduct Implementation Activities}

Once the infrastructure and legal frameworks are determined, actual implementation of the EHR can move forward. Services can be offered to facilitate this implementation with training and advice during the implementation period. The oversight institution can choose to create a task force with the intent of overseeing the different implementation activities and whose responsibility would be to take action to address issues as they arise during implementation.

The field of change management has explored what is needed to successfully implement major changes. For health care specifically, recommendations for engaging staff in the process include four Rs: ensuring that staff understands their roles in the process, making the reason and motivation for the change clear, painting the future desired result clearly, and making the route or path to change possible (Herman, 2011). 
EHR implementations are known to decrease efficiency and therefore volume for a period after uptake. This decreased efficiency is sometimes significant but is usually followed by realization of time and money savings. As a result, part of the implementation effort should include setting expectations for those who will be involved with or affected by the implementation.

\section{Collect Data to Evaluate the Success of the Implementation Efforts}

With the infrastructure in place, the system can begin collecting usage, public health, and outcome data. These will be based on the measures determined earlier. To the extent that they are available and can be collected reliably, baseline data will be important for comparison in order to determine the effect of EHR adoption. Process measures can include the number of patients in the system, the number of prescriptions written in the system, the number of electronic interactions with patients, the number of patients who access their own data, and the number of alerts triggered. Utilization measures will be easier to track for such things as length of stay, number of hospitalizations, and frequency of readmissions.

Outcome measures can include various morbidity and mortality measures; lab values, such as percentage of patients with elevated hemoglobin A1c (a diabetes indicator) or elevated blood pressure; and preventive care use, such as cancer screenings and vaccinations.

\section{Evaluate the Success of Implementation Efforts}

The data collected will allow the government to evaluate the effects of the EHR rollout. The government can ask and answer important questions, including how many doctors and patients are using the system; whether more people are receiving care; whether the care received is of high or low quality; and whether public health measures, such as vaccinations, are being affected. Satisfaction data can also be collected.

\section{Objective 5: Implement a Trackable Computerized Pharmaceutical and Device Ordering System as Part of the Electronic Health Record by 2023}

This section provides advice on steps that should be followed to move from a manual drug and device ordering system to a computer-assisted one. Figure 2.7 presents the timeline for objective 5 activities. 
Figure 2.7. Timeline for Key Activities to Achieve Objective 5

\section{Objective 5: Implement a pharmaceutical and device tracking system as part of the EHR by 2023}

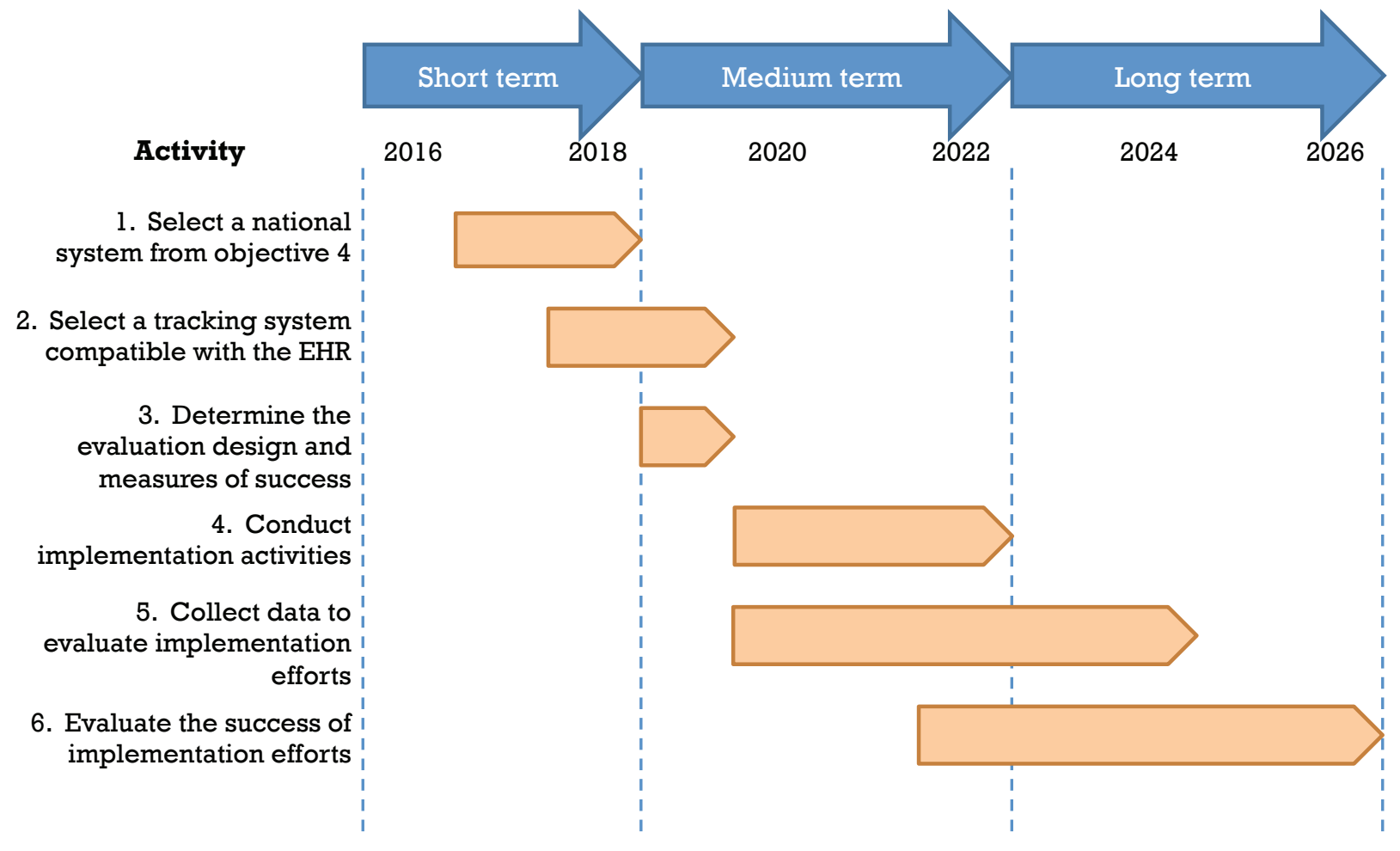

\section{Establish Criteria for System Standards}

To computerize the Chilean drug and device health care system, the first activity is to identify and adopt a single standard coding system for drugs and medical supply tracking. One example is the international coding system called GS1 standards. The Western Metropolitan Healthcare Network and one of the main suppliers of drugs and consumables in the country, the Central Nacional de Abastecimiento, are already actively working to implement these standards to improve stock monitoring and to enable traceability of drugs and medical supplies (Reyes, undated). Further expansion of these efforts might be necessary.

\section{Select a System That Is Compatible with the National Electronic Health Record}

This activity tracks closely the activity in objective 4 related to selection of a national EHR. The options for selecting the national tracking system are the same as those described in the EHR objective. One additional consideration for selection of the tracking system is that it be compatible with the EHR selected for implementation in the public system. This will likely involve consideration of both EHR and tracking system simultaneously, as well as consideration 
of the benefits and drawbacks to selecting a single national system versus identifying standards and allowing different vendors to design compatible systems.

\section{Determine the Evaluation Design and Measures of Success}

So far, the pharmaceutical ordering system is mainly limited to the Santiago metropolitan region. Prior to selecting a national system that multiple clinics outside that area could implement, a detailed pre-analysis evaluation plan with identified suppliers, planned interventions (e.g., alerts on medication shortage, medicine recording and certification, creating a table of clinical information [Reyes, undated] for each drug, collecting logistical data for each product) on short-, medium-, and long-term bases, and measures of success should be identified - in collaboration with key stakeholders, as suggested in the above sections. Possible measures of success include the accuracy of drug and medical device inventory tracking (e.g., number of days with supply shortage of medication or medical devices), number of missed medication dosing of patients in a hospital (e.g., medication error rate), the physician's perception of treatment quality, the patient's health (e.g., underdose or overdose of medication), medication turnaround time, and time spent on patient recalls for medical devices.

\section{Collect Data to Evaluate the Success of the Implementation Efforts}

Data on measures outlined in the above section should be collected and tracked in hospitals and clinics with and without the selected computerized system for later comparison over time, in addition to baseline data. Although some data might be collected electronically, data in the early phases of the project might be unreliable or of poor quality. Therefore, we recommend complementing those data by conducting surveys and semistructured interviews at least every six months.

\section{Conduct Implementation Activities}

Consistently with what we recommended for the other objectives, we recommend scaling up the selected system using two approaches. First, identify hospitals or clinics that have the infrastructure necessary to begin using these tools. Second, encourage health providers and pharmacies in the areas with unforeseen shortages of medicine and other medical supplies to adopt these tools.

These systems require more than just installation of the required hardware systems, such as computers or barcode readers, but might also require a redesign of physical spaces either in hospitals or pharmacies because workflows of those using the health IT product might change significantly as well. Therefore, it is critical to invest in workforce training for everyone involved (e.g., pharmacists, clinical staff, administrative assistants, heads of supply), in terms of technical know-how, management, and general use of these tools (Reyes, undated). Especially in the early implementation phase, additional staff support should be provided. Additionally, incentives designed to encourage utilization of these systems could be implemented. These incentive 
programs would be similar in design to those used in telemedicine or EHR adoption, described in Chapter Three.

\section{Evaluate the Success of the Implementation Efforts}

Regular (e.g., at least every six months) quantitative and qualitative analyses should be applied to prevent mishap or even failure of these systems. Regular measurement is critical because it will allow not only identifying progress but also, especially in the early phases, identifying errors, bottlenecks, and financial and safety risks of the implementation process. Cost-benefit analysis should be applied as well. Because these systems operate within the overall EHR, their costs and benefits will represent a part of the overall evaluation of the EHR systems implemented as part of objective 4 . 


\section{Chapter Three. Establishing Incentives to Encourage Health Information Technology Growth}

In this chapter, we outline financial and nonfinancial incentives that could be applied throughout the implementation process of each of the objectives described above.

\section{Incentives to Adopt and Use Electronic Health Records}

Using electronic health records involves the cost of acquisition, decreased productivity during transition, and, most importantly, a significant change in workflow and culture for providers and their teams. For that reason, adoption has been slow, and many countries have elected to implement incentives to motivate adoption and use of EHRs.

Different countries have created different kinds of incentives, leading to different outcomes. For example, ONC established the meaningful-use program, which set objectives for EHR use by which professionals and hospitals could qualify for incentive payments (and later avoid financial penalties). ONC rolled out these objectives in three stages, with the first (in 2011 and 2012) focused on data capture and sharing; the second (in 2014) focused on clinical processes; and the third focuses on measuring improved outcomes (HealthIT.gov, 2015a).

Stage 1 of meaningful use included such measures as use of electronic medication ordering, alerting for drug-drug interaction checks, recording specific demographics of patients, maintaining accurate allergy and medication lists, recording smoking status, and protecting health information securely. The system required that a minimum percentage of patients have received the relevant item documented in the system. For stage 2, meaningful-use attestation required both higher percentages of use of the current standards and meeting new criteria, including electronic notes, letting patients access their information through a web portal, and providing online secure messaging. Stage 3 focuses on measures of outcomes. Meaningful use is expected to transition in 2016 to support payment reform as laid out in the Medicare Access and CHIP Reauthorization Act of 2015 (Pub. L. 114-10), which moves the United States to a new merit-based payment system.

Meaningful use is an important model to consider for both its strengths and its limitations. The program was quite successful in increasing EHR uptake, but it left the major issue of interoperability for later, and the United States now finds itself with many incompatible systems.

Other countries have approached EHR adoption and incentives quite differently, with varying degrees of success. Chile can also learn from the experiences of other countries.

France and the United Kingdom, for example, tried to institute uniform national systems but ran into problems with patient security, deadlines, and cost (Stone, 2014). As researchers concluded, "Though establishing a national system would allow countries to achieve the final 
stage of interoperability, a country's size, diversity and current health system can determine if this type of implementation is possible" (Stone, 2014, p. 3).

Many countries, including the United States, the United Kingdom, and Australia, have set up pay for performance for use of EHRs. The meaningful-use program was discussed above, and benefits were shown from the program: Physicians with EHRs that met meaningful-use criteria were more likely to report benefits among a range of measures of improved patient care than physicians without such EHRs (King, Patel, Jamoom, \& Furukawa, 2014).

Uptake of EHRs varies greatly across the world. As of 2013, the top ten countries in terms of EHR adoption rates included Norway and the Netherlands with 98\%, down to Canada with 56\% and Switzerland with 41\% (Gregg, 2013). Some of these countries used a pay-for-performance model to increase adoption (the United States is currently at about 70\%), but others did not and still have high adoption, which is much easier in countries where the government controls the health system. Still, even in countries with high adoption rates, many countries are struggling with the challenge of interoperability (Commonwealth Fund, undated).

Alternative incentives and implementation designs might be desirable, depending on how much money is available to invest into the program; paying incentives for adoption can be quite expensive, has not been well-studied, and could lead to unintended consequences, such as providers gaming the system for rewards (Canadian Medical Association, 2014). Alternative designs exist and might be more cost-effective as well. One possibility is that Chile could make software freely available and then motivate its use by making data easily accessible and integrated through that software (public health data, e-prescribing) and making it easy for providers to coordinate with other providers. Patients might also support adoption by preferentially selecting doctors who are on the national system (consumer demand). Other ideas include developing a culture with personal and social reinforcement among care providers or incentivizing vendors to improve functionality of the EHR over time (for example, by changing their remuneration from a software service to a transaction-based model to spur "refinement of enhanced use functionalities," as suggested by a Canadian study, issued as part of its implementation deliberations [Canadian Medical Association, 2014]).

This same Canadian report also pointed out that not spending money to pay for adoption would allow funds to be spent on other things. Instead, money could be spent to improve the experience of using an EHR, for example, or on standardizing and improving the EHR interface (Canadian Medical Association, 2014), supporting tool improvement through research and development, which would then increase uptake. Thus, consideration of the trade-offs associated with funding incentive programs, as opposed to using funds to support other activities that might make adoption and use of EHRs easier, will be an important part of selecting an incentive approach. 


\section{Incentives to Encourage Further Development and Use of Telemedicine}

Evidence shows that telemedicine use is significantly correlated with adopters' perceptions of the benefits that widespread adoption of telemedicine will have for them individually, especially for providers outside of remote areas, and for patients' health (Zanaboni \& Wootton, 2012). We suggest applying both financial and nonfinancial incentives for health providers throughout the implementation process of telemedicine projects.

Nonfinancial incentives could take the form of free training for nurses and physicians and onsite support staff during the early stages of telemedicine project implementation. Sharing the evidence on how the use of telemedicine can increase work efficiency and solve medical issues over time has also proven to be a very successful component in increasing the rate of adoption of telemedicine (Zanaboni \& Wootton, 2012). Some other examples of nonfinancial incentives include public recognition, or even career progression if one is engaged in telemedicine consulting for a certain number of cases per year.

Financial incentives for health practitioners could take the form of a bonus or per-service incentive payment, especially for the early adopters. In the United States, a financial incentive was used initially to encourage physicians to refer patients to telehealth. The bonus paid to physicians was proportional to the number of patients referred into the telehealth programs (Cruickshank, 2012). Australia has been working to implement these and similar financial incentives for clinicians since 2011, in addition to providing financial incentives to facilities that are willing to host telehealth services and equipment (Telemedicine Australia, undated). Similarly, the U.S. Department of Agriculture granted more than $\$ 30$ million to support linkages between hospitals and installation of telemonitoring and related equipment ("The Telehealth Year in Review," 2011).

Providing incentives for patients could also increase use, demand, and expectations for EHRs. Simply providing excellent tools that patients want to use can increase demand. For example, patients who like their personal health records might choose other doctors using the same EHR system so they can easily see all their data in the same place. For those without Internet access, providing public access or subsidizing personal access can lead to more use and again more demand. Workshops at the local clinics or hospitals or even community events could present not only benefits of telemedicine use (either via personal experience sharing or dissemination of results based on rigorous evaluations) but also an explanation about how to properly use the tools. The latter is especially important in areas with low digital literacy (e.g., rural areas) and for older adults. 



\section{Chapter Four. Conclusions}

This report presents a roadmap for the development of health IT in Chile over the short, medium, and long terms. We recommend focusing on five primary objectives that fall into two groups: first, the development of institutional capacity to monitor and facilitate new implementation activities; and second, four objectives related to the expansion of specific health IT projects. Determining the resources necessary to implement the roadmap will be an important early activity for an oversight institution (created as part of objective 1) but was beyond the scope of this project. Our recommendations focus on offering general guidelines for the oversight institution to follow in implementing these objectives, based on our background research as part of the environmental scan and key informant interviews.

\section{Limitations}

This study has some limitations. The first limitation is the lack of estimates related to the inputs and resources necessary to achieve the roadmap objectives. Given the scope of this project and timeline, as well as a lack of available information regarding current projects in Chile and their associated resources and costs, we could not calculate these estimates. However, we do provide guidance regarding the types of resources that might be needed to achieve the objectives.

A second limitation is the fact that we conducted our key informant interviews with ten respondents. This limited sample of important policymakers and health IT project leaders gave us a picture of the current health IT environment and potential challenges to growth but might not have captured the complete picture of potential issues the roadmap will face. However, to try to ensure that we incorporated as much information as possible, we conducted a briefing for the board of governors and other interested stakeholders in order to obtain feedback on the proposed roadmap design. We have incorporated this feedback into the roadmap.

A third limitation is the lack of publicly available information regarding how the Chilean health care system works in practice. This made it difficult to recommend specific incentive programs that might produce the desired level of uptake of a given health IT project within the Chilean system context. However, we do present descriptions of incentive programs that other countries have used, and we expect that the oversight institution can use these descriptions as a starting point to design an incentive system appropriate for the Chilean health care system. 


\section{Recommendations}

Informed by our background research and the experience designing the roadmap, we have three recommendations for the oversight institution:

1. Develop the health IT workforce and other resources needed to successfully implement health IT projects. During our background research, we identified the small health IT workforce as a challenge to successful health IT implementation. Emphasize developing the inputs and resources necessary to achieve the roadmap objectives early in the process.

2. Use incentive programs to encourage successful implementation of health IT projects. We describe different incentive programs that different countries have used to encourage the implementation and use of EHRs and telemedicine. The oversight institution should carefully study these programs and select the characteristics that might best align incentives to achieve the desired objectives in the Chilean system context.

3. Clearly define measures of success, and consistently collect baseline and follow-up data to assess success. The ability to assess the extent to which the objectives have been met will be an important factor in determining any next steps for the implementation of health IT in Chile.

\section{Conclusions}

This roadmap is intended as a guide for the government of Chile and key health IT stakeholders to use in expanding the use of and encouraging further development of health IT in Chile over the coming ten years. We have developed five objectives for the roadmap; within each objective, we identify important activities necessary to achieve the given objective. For each objective and activity, we also offer recommendations as to the time frame (short, medium, and long term) for each activity, which might be useful for planning purposes. Finally, we present three recommendations designed to focus implementation efforts on key activities.

Health IT might present an opportunity to address broader health care system challenges, such as access, quality of care, and high spending on health care. The oversight institution, as well as the different government ministries involved in the roadmap activities, should carefully consider any long-term objectives related to broad health care system changes that might be measured as part of the health IT implementation efforts. Although it is beyond the scope of this project to suggest specific measures and an approach to evaluating this roadmap's effect on broader health system outcomes, we do recommend consideration of these effects in designing midterm evaluations for each objective. Evaluation of broader effects might help guide further efforts to improve the quality of care and access and to reduce spending on health care in Chile. 


\section{References}

Alcayaga, Claudia, Janet Carola Pérez, Claudia Bustamante, Solange Campos, Ilta Lange, and Francisca Zuñiga, "Plan piloto del sistema de comunicación y seguimiento móvil en salud para personas con diabetes," [Pilot plan for a mobile health communication and monitoring system for people with diabetes], Revista Panamericana de Salud Pública, Vol. 35, No. 5-6, 2014, pp. 458-464.

Asociación Chilena de Informática en Salud, "Telemedicine and e-Health Projects Overview in Chile," version 1.1, October 17, 2011. As of April 27, 2016: http://www.achisa.org/PDF/Resumen_Finlandia_v1p1.pdf

Canadian Medical Association, How Can Canada Achieve Enhanced Use of Electronic Medical Records? May 2014. As of April 27, 2016:

https://www.cma.ca/Assets/assets-library/document/en/advocacy/Enhanced-Use-of-EMRsDiscussion-Paper-Final-May-2014.pdf

Capurro, Daniel, "Health Informatics in Chile: Responding to Health Reforms," Health Information and Libraries Journal, Vol. 24, No. 4, December 2007, pp. 287-291.

Commonwealth Fund, "What Is the Status of Electronic Health Records?" undated. As of April 27, 2016:

http://international.commonwealthfund.org/features/ehrs/

Cruickshank, John, Telehealth: What Can the NHS Learn from Experience at the US Veterans Health Administration? London: 2020health.org, January 2012. As of April 27, 2016:

http://www.2020health.org/dms/2020health/downloads/reports/Telehealth-VA/Telehealth VA.pdf

EU-See European Union.

European Union, "Directive 95/46/EC of the European Parliament and of the Council of 24 October 1995 on the Protection of Individuals with Regard to the Processing of Personal Data and on the Free Movement of Such Data," Official Journal L 281, November 23, 1995, pp. 31-50. As of April 28, 2016:

http://eur-lex.europa.eu/LexUriServ/LexUriServ.do?uri=CELEX:31995L0046:en:HTML

- "Directive 2002/58/EC of the European Parliament and of the Council of 12 July 2002 Concerning the Processing of Personal Data and the Protection of Privacy in the Electronic Communications Sector (Directive on Privacy and Electronic Communications)," Official Journal L 201, July 31, 2002, pp. 37-47. As of April 28, 2016:

http://eur-lex.europa.eu/LexUriServ/LexUriServ.do?uri=CELEX:32002L0058:en:HTML 
Federation of State Medical Boards, Model Policy for the Appropriate Use of Telemedicine Technologies in the Practice of Medicine, Washington, D.C., April 2014. As of April 28, 2016:

https://www.fsmb.org/Media/Default/PDF/FSMB/Advocacy/FSMB_Telemedicine_Policy.pd $\mathrm{f}$

Fernández, Andrés, and Enrique Oviedo, eds., e-Health in Latin America and the Caribbean: Progress and Challenges, Santiago, Chile: United Nations, July 2011. As of April 27, 2016: http://www.cepal.org/en/publications/3001-e-health-latin-america-and-caribbean-progressand-challenges

FONASA—See Fondo Nacional de Salud.

Fondo Nacional de Salud, "Iniciativa pionera en Chile y Latinoamérica permitirá monitorear a distancia a pacientes crónicos con Diabetes y enfermedades cardiovasculares," Asegurados, November 7, 2014. As of April 27, 2016:

https://www.fonasa.cl/portal_fonasa/site/artic/20141107/pags/20141107083052.html

—_ "FONASA lanza compra de Bono Consulta Médica a través de la Web," Asegurados, May 7, 2015. As of April 27, 2016:

https://www.fonasa.cl/portal_fonasa/site/artic/20150507/pags/20150507131233.html

Global Growth Markets, “Accuhealth Improving Lives in Chile," December 29, 2015. As of April 27, 2016:

http://ggmkts.com/i-Accuhealth-improving-lives-in-Chile

GlobalMed, "Security and Privacy with Telehealth," undated. As of April 27, 2016:

https://www.globalmed.com/additional-resources/security-and-privacy-with-telehealth

Gregg, Helen, “Top 10 Countries for EHR Adoption,” Becker's Health IT \& CIO Review, June 27, 2013. As of April 27, 2016:

http://www.beckershospitalreview.com/healthcare-information-technology/top-10-countriesfor-ehr-adoption.html

HealthIT.gov, "What Is EHR Interoperability and Why Is It Important?" last updated January 15, 2013. As of April 27, 2016:

https://www.healthit.gov/providers-professionals/faqs/what-ehr-interoperability-and-why-itimportant

__ , "Meaningful Use Definition and Objectives," February 6, 2015a. As of April 27, 2016: https://www.healthit.gov/providers-professionals/meaningful-use-definition-objectives

—_, "Benefits of Electronic Health Records (EHRs)," last updated July 30, 2015b. As of April 27, 2016:

https://www.healthit.gov/providers-professionals/benefits-electronic-health-records-ehrs 
Health Level Seven International, "FHIR Overview," generated October 24, 2015. As of April 27, 2016:

https://www.hl7.org/fhir/overview.html

Herman, Bob, "Shifting Cultures: A Change Management Guide for Hospital Leaders," Becker's Hospital Review, November 22, 2011. As of April 27, 2016:

http://www.beckershospitalreview.com/hospital-management-administration/shiftingcultures-a-change-management-guide-for-hospital-leaders.html

Joseph, Victor, Robert M. West, Darren Shickle, Justin Keen, and Susan Clamp, "Key Challenges in the Development and Implementation of Telehealth Projects," Journal of Telemedicine and Telecare, Vol. 17, No. 2, March 2011, pp. 71-77.

King, Jennifer, Vaishali Patel, Eric W. Jamoom, and Michael F. Furukawa, "Clinical Benefits of Electronic Health Record Use: National Findings," Health Services Research, Vol. 49, No. 1, Pt. 2, February 2014, pp. 392-404.

Kodukula, Subrahmanyam, and Mariyam Nazvia, "Evaluation of Critical Success Factors for Telemedicine Implementation," International Journal of Computer Applications, Vol. 12, No. 10, January 2011, pp. 29-36.

Mathematica Policy Research and Harvard School of Public Health, Health Information Technology in the United States 2015: Transition to a Post-HITECH World, September 18, 2015. As of April 27, 2016:

http://www.rwjf.org/en/library/research/2015/09/health-information-technology-in-theunited-states-2015.html

Ministerio de Salud de Chile, Mapa de ruta: Plan estratégico de tecnologías de información (esalud) 2011-2020, April 2013. As of April 27, 2016:

http://www.salud-e.cl/wp-content/uploads/2013/08/Mapa-de-ruta-completo.pdf

MINSAL—See Ministerio de Salud de Chile.

NORC at the University of Chicago, Evaluation of the Information Technology Professionals in Health Care ("Workforce") Program: Summative Report, March 2014. As of April 27, 2016 : https://www.healthit.gov/sites/default/files/workforceevaluationsummativereport.pdf

Pan American Health Organization and World Health Organization, "Chile Implements Electronic Medical Leave Project for FONASA Beneficiaries," undated. As of November 19, 2015:

http://www.paho.org/ICT4Health/index.php?option=com_content\&view=article\&id=161\&It emid=204\&lang=en 
Piette, John D., Joaquin A. Blaya, Ilta Lange, and Juan B. Bru Sanchis, Experiences in mHealth for Chronic Disease Management in 4 Countries, paper presented at the Fourth International Symposium on Applied Sciences in Biomedical and Communication Technologies, Barcelona, October 2011.

Public Law 104-191, Health Insurance Portability and Accountability Act of 1996, August 21, 1996. As of April 28, 2016:

https://www.gpo.gov/fdsys/pkg/PLAW-104pub1191/html/PLAW-104publ191.htm

Public Law 114-10, Medicare Access and CHIP Reauthorization Act of 2015, April 16, 2015. As of April 28, 2016:

https://www.congress.gov/114/plaws/publ10/PLAW-114publ10.pdf

Reyes, Carolina Cerón, "Improving Quality of Care and Patient Safety in Chile: Servicio de Salud Metropolitano Occidente," 2010/2011 GS1 Healthcare Reference Book, undated. As of April 27, 2016:

http://www.gs1.org/sites/default/files/docs/casestudies/Case_study_Chile_traceability.pdf

Stone, Christine P., A Glimpse at EHR Implementation Around the World: The Lessons the US Can Learn, Health Institute for E-Health Policy, May 2014. As of April 27, 2016: http://www.ehealthpolicy.org/docs/A_Glimpse_at_EHR_Implementation_Around_the_World1_ChrisSton e.pdf

Taylor, Erin Audrey, Shira H. Fischer, Tadeja Gracner, Ivo Tejeda, Alice Kim, Emilio ChavezHerrerias, and Fernando Hoces de la Guardia, Developing a Strategic Program for Chilean Health Information Technology: Environmental Scan and Key Informant Interviews, Santa Monica, Calif.: RAND Corporation, RR-1358/1-CME, 2016. As of April 28, 2016: http://www.rand.org/pubs/research_reports/RR1358z1.html

Telemedicine Australia, "Telehealth, Modernising Medicare," undated. As of April 27, 2016: http://www.telemedicineaustralia.com.au/telehealth_FinancialIntensive

“The Telehealth Year in Review," Government Health IT, December 29, 2011. As of April 27, 2016: http://www.govhealthit.com/news/telehealth-year-review

Toledo, J., R. Roca, J. A. Antón, J. L. Martin de Nicolás, G. Varela, and P. Yuste, “Conservative and Bronchoplastic Resection for Bronchial Carcinoid Tumours," European Journal of Cardio-Thoracic Surgery, Vol. 3, No. 4, 1989, pp. 288-291.

World Health Organization, "International Classification of Diseases (ICD)," undated. As of April 27, 2016:

http://www.who.int/classifications/icd/en/ 
Zanaboni, Paolo, and Robert Wootton, "Adoption of Telemedicine: From Pilot Stage to Routine Delivery," BMC Medical Informatics and Decision Making, Vol. 12, No. 1, December 2012, pp. $1-9$. 